Charlotte Christiansen

Level-ARCH Short Rate Models with Regime Switching:

Bivariate Modeling of US and European Short Rates

Finance

Research Group

Department of Accounting,

Finance and Logistics 


\section{Level-ARCH Short Rate Models with Regime Switching:}

Bivariate Modeling of US and European Short Rates

Charlotte Christiansen*

Aarhus School of Business

April 7, 2005

\footnotetext{
${ }^{*}$ Charlotte Christiansen, Finance Research Group, Aarhus School of Business, Fuglesangs Alle 4, 8210 Aarhus V, Denmark. +45 89486691 (phone), +45 89486660 (fax), mail@CharlotteChristiansen.dk (mail).
} 


\title{
Level-ARCH Short Rate Models with Regime Switching: \\ Bivariate Modeling of US and European Short Rates
}

\begin{abstract}
This paper introduces regime switching volatility into levelARCH models for the short rates of the US, the UK, and Germany. Once regime switching and level effects are included there are no gains from including ARCH effects. It is of secondary importance exactly how the regime switching is specified. The estimated level parameters are very different across countries. The corresponding new bivariate models for the US and UK short rates show that the states of the US and UK short rate volatilities are not independent nor identical. Equivalently, the US and German volatility states are neither independent nor identical.
\end{abstract}

Keywords: Bivariate short-rate model; International short rates; LevelARCH model; Regime Switching.

JEL Classifications: G12; G15; E43; C32. 


\section{Introduction}

This paper models short rates. The starting point is the short rate model of Chan, Karolyi, Longstaff \& Sanders (1992) where the conditional volatility of the short rate changes is proportional to the $\gamma$ th power of the level of the short rate itself; the CKLS level model. By imposing different restrictions on $\gamma$ various well-known short rate models are obtainable, e.g. when $\gamma \equiv \frac{1}{2}$ the square root model of Cox, Ingersoll \& Ross (1985) emerges. In Chan et al. (1992) $\gamma$ is a free parameter and it is estimated to be approximately $1 \frac{1}{2}$ which is considered unreasonably large. Previous literature has extended the CKLS level model to also include ARCH volatility. Introducing heteroskedasticity into the conditional volatility reduces the estimate of $\gamma$. Moreover, short rate models including both level and heteroskedasticity effects are superior to models comprising only one or the other effect. On the other hand, previous literature has shown that regime switching models are generally preferable to single regime models. In this paper we further introduce regime switching conditional volatility into the level-ARCH model. In one model specification, the $\gamma$ parameter is state dependent whereby we are able to investigate which short rate models apply in the two states.

Another contribution of this paper is to extend the regime-switching level-ARCH model to a bivariate setting to describe the short rates of the US and the UK simultaneously. No restrictions are imposed on the transition probabilities. This enables us to analyze the interdependence of the volatility states of the world's largest economy and the most important European economy outside the euro area. Similar analysis is conducted for the US and German short rates, whereby we analyze the relation between the volatility states of the US and the most important euro country.

Various specifications of level-ARCH short rate models have been analyzed in univariate frameworks, e.g. by Longstaff \& Schwartz (1992), Brenner, Harjes \& Kroner (1996), and Koedjik, Nisssen, Schotman \& Wolff (1997). Using dummy variables, the previous literature has documented a structural shift in the parameters of the CKLS level model around the Monetary Experiment of the Federal Reserve, cf. Bliss \& Smith (1998) and Dell'Aquila, Ronchetti \& Trojani (2003). Furthermore, Dewachter (1996) and Dahlquist \& Gray (2000) estimate the CKLS level model with truly regime switching parameters.

The previous literature has investigated short rate models with both 
regime switching volatility, level effects, and $\mathrm{ARCH}$ volatility. But (as far as the authors are aware) only with stronger assumptions than those applied here. In particular, Gray (1996) estimates the square root model $\left(\gamma \equiv \frac{1}{2}\right)$ where the $\mathrm{ARCH}$ process is regime switching. In contrast, in our model $\gamma$ is an estimated parameter. And regime switching either occurs in the $\gamma$ parameter or in the ARCH process. Smith (2002) uses a short rate model with regime switching stochastic volatility (in place of $\mathrm{ARCH}$ volatility). Although $\gamma$ is an estimated parameter, it is not allowed to be state dependent.

The previous literature has offered bivariate short rate models, but (to our knowledge) not with both regime switching, level, and ARCH effects as we suggested here. Christiansen (2005) uses a bivariate level-ARCH model without regime switching to describe the long rate and the spread between the long and short rate. Ferreira (forthcoming) applies a bivariate non-switching level-ARCH model to describe German and French short rate changes. Ang \& Bekaert (2002) apply various trivariate models for the US, $\mathrm{UK}$, and German short rates. In the level specification $\gamma \equiv \frac{1}{2}$ and $\mathrm{ARCH}$ effects are not included.

The main findings of the paper can be summarized as follows. Once the univariate short rate model includes level effects and regime switching, there are no advantages of the conditional volatility following an ARCH process. This applies to all three countries. Moreover, it is undecided whether it is preferable that the regime switching occurs by letting the level parameter $(\gamma)$ or the volatility $(\sigma)$ be state dependent. For the US when $\gamma$ is state dependent the following applies: In the low variance state the Cox et al. (1985) square root model applies $\left(\gamma=\frac{1}{2}\right)$ and in the high variance state the Cox, Ingersoll \& Ross (1980) model applies $\left(\gamma=1 \frac{1}{2}\right)$. The applicable short rate models are very different for the two European countries. When the level parameter is not allowed to be state dependent, no well-known short rate model applies, $\gamma \in\left(1 ; 1 \frac{1}{2}\right)$, and it amounts to averaging across the two states. Again, the estimated level parameters are very different for the UK and Germany.

The bivariate short rate modeling for the US and UK short rates provide unaltered conclusions regarding the short rate volatilities. We find that the states of the US and UK short rate volatilities are not independent. Furthermore, the volatility states of the US and UK short rates are not identical, 
i.e. they are not in the same volatility state at the same time. Equivalently, the states of the US and German short rates are neither independent nor identical.

The remaining part of this paper is structured as follows. In Section 2 the regime-switching short rate models are introduced; first we provide the one-country models which are subsequently extended to a two-country setting. Section 3 introduces the short rate data and presents the empirical results: First the country-by-country results are discussed followed by the US-UK results and finally the US-German results. Section 4 concludes.

\section{Regime-Switching Short Rate Model}

In this section we introduce the econometric framework we use to describe the short rates. Firstly, we introduce a univariate regime-switching model with level and heteroskedasticity effects. Secondly, we present a bivariate extension hereof that describes the evolution of two short rate series simultaneously.

\subsection{Univariate Short-Rate Model}

\subsubsection{CKLS Level Model}

Here we describe the evolution of the short rate country by country. The model takes its offspring in the CKLS level model for the short rate $\left(r_{t}\right)$, cf. Chan et al. (1992), namely the continuous-time diffusion:

$$
d r_{t}=\left(\alpha_{0}+\alpha_{1} r_{t}\right) d t+\sigma r_{t}^{\gamma} d Z_{t}
$$

where $Z_{t}$ is a standard Brownian motion. The conditional mean of the short rate changes depends on the short rate, and the short rate process is mean reverting for $\alpha_{1}<0$. The conditional volatility of the short rate changes depends on the level of the short rate, in fact it is proportional to the $\gamma$ th power of the level of the short rate. The level parameter $\gamma$ is non-negative. The larger $\gamma$ is the more important the level of the short rate is for the conditional volatility. Various well-known term structure models are nested in the CKLS level model and are obtainable by imposing different restrictions on $\gamma$. For $\gamma \equiv 0$ the Vasicek (1977) model is obtained, for $\gamma \equiv \frac{1}{2}$ the squareroot model of Cox et al. (1985), for $\gamma \equiv 1$ the Brennan \& Schwartz (1980) 
model, and for $\gamma \equiv 1 \frac{1}{2}$ the Cox et al. (1980) model.

In the empirical analysis Chan et al. (1992) use a discrete version of the diffusion process in equation (1):

$$
r_{t}-r_{t-1}=\alpha_{0}+\alpha_{1} r_{t-1}+\epsilon_{t}
$$

where the residual $\epsilon_{t}$ has mean zero and conditional variance

$$
E\left[\epsilon_{t}^{2}\right]=h_{t}=\sigma^{2} r_{t-1}^{2 \gamma}
$$

As in the continuous-time framework, the short rate is mean reverting for $\alpha_{1}<0$, and the volatility of the short rate is proportional to the $\gamma$ th power of the short rate last period. Although, the volatility of the short rate changes is time-varying it is not persistent. Chan et al. (1992) find an estimate of $\gamma$ equal to around $1 \frac{1}{2}$ which is in accordance with the Cox et al. (1980) model, but is at odds with the theoretically preferred square-root model of Cox et al. (1985) in which $\gamma$ equals $\frac{1}{2}$. The estimated $\gamma$ is therefore considered too high.

\subsubsection{Level-ARCH Models}

The CKLS level model has been extended to accommodate heteroskedasticity effects as well by assuming that the volatility of the short rate changes follow a GARCH-type model, cf. Engle (1982) and Bollerslev (1986). These level-GARCH models are empirically preferred to both level models and GARCH models. A popular level-GARCH specification is contained in Brenner et al. (1996). ${ }^{1}$ The mean of the short rate evolves unchanged according to the CKLS level model in equation (2). The residual $\epsilon_{t}$ still has zero mean, but its conditional variance is slightly different:

$$
h_{t}=\sigma_{t}^{2} r_{t-1}^{2 \gamma}
$$

The only difference is that the $\sigma_{t}^{2}$ is now time varying. The heteroskedasticity is introduced by assuming that $\sigma_{t}^{2}$ evolves according to a GARCH-type specification, e.g. the $\operatorname{GARCH}(1,1)$ model. In this manner the short rate model of Brenner et al. (1996) includes both level effects and heteroskedasticity effects. Level-GARCH models for the short rate changes has also been

\footnotetext{
${ }^{1}$ Here we apply their "time-varying parameter" specification.
} 
applied by e.g. Longstaff \& Schwartz (1992), Andersen \& Lund (1997), Koedjik et al. (1997), and Bali (2000a, 2000b).

The previous literature finds that there are structural breaks in the short rate volatility. Bliss \& Smith (1998) and Dell'Aquila et al. (2003) use dummy variables to find evidence that the parameters in the CKLS level model incur a structural break around the Monetary Experiment in 1979-1982. Dewachter (1996) and Dahlquist \& Gray (2000) apply a CKLS level model with regime switching parameters.

\subsubsection{Regime-Switching Level-ARCH Models}

We suggest to use a regime-switching ARCH specification to describe the evolution of $\sigma_{t}^{2}$. In this way we combine previous findings of regime-switching volatility, level effects, and heteroskedasticity effects. The state of the economy is defined by the level of the volatility of the short rate changes, this is explained in more detail shortly. A first-order two-state Markov chain is assumed. $^{2}$ The state of the economy at time $t$ is denoted $s_{t}$. At each point in time the economy is either in state 1 or state $2 ; s_{t} \in\{1,2\}$. The probability that $s_{t}$ equals, say, 1 depends only on the value of the state variable last period, $s_{t-1}$. We assume constant transition probabilities:

$$
P=\left(\begin{array}{cc}
p_{11} & 1-p_{22} \\
1-p_{11} & p_{22}
\end{array}\right)
$$

where e.g. $p_{11}$ is the probability that the economy was in state 1 last period and is in state 1 this period; $p_{11}=\operatorname{prob}\left[s_{t}=1 \mid s_{t-1}=1\right]$. Hereby the unconditional probability of being in e.g. state 1 is constant:

$$
\operatorname{prob}\left[s_{t}=1\right]=\frac{1-p_{22}}{2-p_{11}-p_{22}}
$$

To access which state the economy is in at a given point in time, the smoothed probabilities are used. The smoothed probability of being in state $i$ at time $t$ is based on all observations in the sample; $\operatorname{prob}\left[s_{t}=i \mid \Phi_{T}\right]$ where $T$ is the last observation in the sample. When the smoothed probability of being in state $i$ at time $t$ is larger than 0.5 the economy is said to be in state $i$ at time $t$. $22)$.

${ }^{2}$ More information on regime switching models is available in Hamilton (1994, Chapter 
Previous literature provides evidence that the most important part of the model specification stems from the variance part, cf. e.g. Durham (forthcoming). Moreover, informal investigations provide no evidence of regime switching in the mean equation. Therefore, the mean equation for the short rate changes is unaltered as in the level CKLS model in equation (2).

The regime switching enters into the variance specification. State 1 is the low variance state and state 2 is the high variance state. The regime dependence of the conditional variance as specified in equation (4) can occur either from the specification of $\sigma_{t}^{2}$ or from the specification of $\gamma$. It is not sensible to make both $\sigma_{t}^{2}$ and $\gamma$ regime dependent at the same time because then it is not possible to distinguish conclusively between the low and the high variance regimes. ${ }^{3}$

First, we let the regime switching enter via $\sigma_{t}^{2}$, and $h_{t}$ is still given by equation (4). Moreover, $\sigma_{t}^{2}$ is still assumed to evolve according to a heteroskedastic model, but not the $\operatorname{GARCH}(1,1)$ as in Brenner et al. (1996). By introducing regime switching into the volatility process we accommodate for the finding in Laumoreux \& Lastrapes (1990) that unaccounted structural changes in the volatility process might exaggerate the persistence of the volatility process. The simplest way to include both regime switching and heteroskedasticity in the volatility process, is by using the switching ARCH(1) model suggested independently by Hamilton \& Susmel (1994) and Cai (1994). Here we apply the latter specification.

$$
\sigma_{t}^{2}=\beta_{0}\left(s_{t}\right)+\beta_{1} \varepsilon_{t-1}^{2}
$$

where $\beta_{0}\left(s_{t}\right)=\left\{\begin{array}{l}\beta_{01} \\ \beta_{02}\end{array}\right.$. The following restrictions are imposed to ensure that the conditional variance is strictly positive and non-exploding: $\beta_{01}, \beta_{02}>0$ and $\beta_{1} \leq 1$. We distinguish between the two states by the size of the $\beta_{0}\left(s_{t}\right)$ parameters, thus, we impose the following restriction in the estimation:

$$
\beta_{01} \leq \beta_{02}
$$

\footnotetext{
${ }^{3}$ If $\sigma_{t}^{2}$ is in the low regime, then $\gamma$ must also be in the low regime in order to conclude unambiguously that the economy is in the low variance regime. Informal studies show that the parameters in $\sigma_{t}^{2}$ and $\gamma$ compensate each other, so that when the former is large the latter is small and vice versa.
} 
whereby state 1 is the low variance state, and state 2 the high variance state.

A second option is to let the $\gamma$ parameter in equation (4) be state dependent; $\gamma\left(s_{t}\right)=\left\{\begin{array}{l}\gamma_{1} \\ \gamma_{2}\end{array}\right.$. Thus, the conditional variance for the short rate changes is

$$
h_{t}=\sigma_{t}^{2} r_{t-1}^{2 \gamma\left(s_{t}\right)}
$$

In order to make state 1 the low variance state again the following restriction is imposed during estimation:

$$
\gamma_{1} \leq \gamma_{2}
$$

The $\sigma_{t}^{2}$ process is now assumed to be a simple $\mathrm{ARCH}(1)$ process without regime switching:

$$
\sigma_{t}^{2}=\beta_{0}+\beta_{1} \varepsilon_{t-1}^{2}
$$

The two specifications are nested in the following general volatility equation:

$$
h_{t}=\sigma_{t}^{2} r_{t-1}^{2 \gamma\left(s_{t}\right)} \text { where } \sigma_{t}^{2}=\beta_{0}\left(s_{t}\right)+\beta_{1} \varepsilon_{t-1}^{2}
$$

when appropriate parameter restrictions are imposed.

In the empirical analysis we estimate six models that all have the same mean equation given in equation (2) and variance specifications that are special cases of equation (12).

- I: Level model

$$
h_{t}=\sigma_{t}^{2} r_{t-1}^{2 \gamma} \text { where } \sigma_{t}^{2}=\beta_{0}
$$

- II: Level ARCH model

$$
h_{t}=\sigma_{t}^{2} r_{t-1}^{2 \gamma} \text { where } \sigma_{t}^{2}=\beta_{0}+\beta_{1} \varepsilon_{t-1}^{2}
$$

- III: Switching-level ARCH model

$$
h_{t}=\sigma_{t}^{2} r_{t-1}^{2 \gamma\left(s_{t}\right)} \text { where } \sigma_{t}^{2}=\beta_{0}+\beta_{1} \varepsilon_{t-1}^{2} \text { and } \gamma\left(s_{t}\right)=\left\{\begin{array}{l}
\gamma_{1} \\
\gamma_{2}
\end{array}\right.
$$

- IV: Level SWARCH model

$$
h_{t}=\sigma_{t}^{2} r_{t-1}^{2 \gamma} \text { where } \sigma_{t}^{2}=\beta_{0}\left(s_{t}\right)+\beta_{1} \varepsilon_{t-1}^{2} \text { and } \beta_{0}\left(s_{t}\right)=\left\{\begin{array}{l}
\beta_{01} \\
\beta_{02}
\end{array}\right.
$$

- V: Switching-level model 


$$
h_{t}=\sigma_{t}^{2} r_{t-1}^{2 \gamma\left(s_{t}\right)} \text { where } \sigma_{t}^{2}=\beta_{0} \text { and } \gamma\left(s_{t}\right)=\left\{\begin{array}{c}
\gamma_{1} \\
\gamma_{2}
\end{array}\right.
$$

- VI: Level switching-volatility model

$$
h_{t}=\sigma_{t}^{2} r_{t-1}^{2 \gamma} \text { where } \sigma_{t}^{2}=\beta_{0}\left(s_{t}\right) \text { and } \beta_{0}\left(s_{t}\right)=\left\{\begin{array}{c}
\beta_{01} \\
\beta_{02}
\end{array}\right.
$$

Two models are not regime switching; model I is the CKLS level model and model II is the level-ARCH model. Model III has a switching level parameter and ARCH volatility. Model IV has a constant level parameter and SWARCH volatility. Furthermore, we estimate regime switching models without heteroskedasticity; firstly in model $\mathrm{V}$ the level parameter is state dependent and the volatility constant, and secondly in model VI the level parameter is constant and the volatility parameter is constant in each regime.

Previous papers have also applied regime switching models for the short rate changes that include both level and heteroskedasticity effects, but with stronger assumptions on the $\gamma$ parameter. The well-known paper by Gray (1996) is such an example. In Gray (1996) the level parameter is assumed fixed at $\frac{1}{2}\left(\gamma \equiv \frac{1}{2}\right)$, thus restricted to the square-root model whereas he uses a new SWARCH model to describe $\sigma_{t}^{2}$.

Dahlquist \& Gray (2000) estimate regime switching CKLS level models with $\gamma \equiv \frac{1}{2}$ imposed. Another example is contained in Smith (2002) who uses a model with non-switching level effects, but regime switching stochastic volatility.

\subsection{Bivariate Short-Rate Model}

Here we introduce a model that describes the evolution of two countries' short rate changes simultaneously as well as their interdependence. The bivariate model is an extension of the regime switching level-ARCH models introduced above. We are not aware of any bivariate models for short rate changes that include regime switching, level effects, and heteroskedasticity effects. Related papers include Christiansen (2005) who finds that a bivariate level-GARCH model for the long rate changes and (long rateshort rate) spread changes is preferred above a bivariate level model and a bivariate GARCH model. Ferreira (forthcoming) uses a bivariate levelGARCH model to describe the German and French short rate changes. Ang 
\& Bekaert (2002) apply various trivariate models for the US, UK, and German short rates (not short rate changes as is usual). The specification that includes level effects assumes the Cox et al. (1985) specification (with $\gamma \equiv \frac{1}{2}$ ) and does not include ARCH effects. Unlike our model, the transition probabilities for each country are assumed independent, more hereon follows.

We model the short rate changes for country $i=1,2$ (throughout, the $i$ in superscript indicates country $i$ ). The mean equations are as in the univariate model:

$$
r_{t}^{i}-r_{t-1}^{i}=\alpha_{0}^{i}+\alpha_{1}^{i} r_{t-1}^{i}+\epsilon_{t}^{i}
$$

So are the conditional variance equations of the residuals, $\varepsilon_{t}^{i}$.

$$
h_{t}^{i}=\left(\sigma_{t}^{i}\right)^{2}\left(r_{t-1}^{i}\right)^{2 \gamma\left(s_{t}^{i}\right)} \text { where }\left(\sigma_{t}^{i}\right)^{2}=\beta_{0}^{i}\left(s_{t}^{i}\right)+\beta_{1}^{i}\left(\varepsilon_{t-1}^{i}\right)^{2}
$$

where $\beta_{0}^{i}\left(s_{t}\right)=\left\{\begin{array}{l}\beta_{01}^{i} \\ \beta_{02}^{i}\end{array}\right.$ and $\gamma^{i}\left(s_{t}\right)=\left\{\begin{array}{l}\gamma_{1}^{i} \\ \gamma_{2}^{i}\end{array}\right.$. The conditional correlation between $\varepsilon_{t}^{1}$ and $\varepsilon_{t}^{2}$ is assumed to be constant $(\rho)$ as in the Constant Conditional Correlation model in Bollerslev (1990). Note, that the correlation is assumed to be constant across states. Hereby, the conditional covariance is proportional to the conditional volatilities:

$$
h_{t}^{12}=\rho \sqrt{h_{t}^{1} h_{t}^{2}}
$$

Notice that there is a state variable for each country, $s_{t}^{1}=1,2$ and $s_{t}^{2}=1,2$. This implies that country 1 and 2 are not necessarily in the same volatility state at the same time. As in the univariate case, either the ARCH parameter $\left(\beta_{0}^{i}\left(s_{t}\right)\right)$ is regime dependent or the level parameter $\left(\gamma\left(s_{t}\right)\right)$ is regime dependent. With SWARCH, the following restrictions are imposed to make states 1 the low volatility regimes:

$$
\beta_{01}^{1} \leq \beta_{02}^{1} \text { and } \beta_{01}^{2} \leq \beta_{02}^{2}
$$

In the case of switching in the level parameter, the following restrictions are imposed:

$$
\gamma_{1}^{1} \leq \gamma_{2}^{1} \text { and } \gamma_{1}^{2} \leq \gamma_{2}^{2}
$$

Combining two countries each with two volatility states, there are in total four joint states: 


$$
\begin{aligned}
& s_{t}^{*}=1 \text { for } s_{t}^{1}=1 \text { and } s_{t}^{2}=1 \\
& s_{t}^{*}=2 \text { for } s_{t}^{1}=1 \text { and } s_{t}^{2}=2 \\
& s_{t}^{*}=3 \text { for } s_{t}^{1}=2 \text { and } s_{t}^{2}=1 \\
& s_{t}^{*}=4 \text { for } s_{t}^{1}=2 \text { and } s_{t}^{2}=2
\end{aligned}
$$

In state 1 both countries are in their low variance states, whereas in state 4 they are both in the high variance states. In states 2 and 3 there is one country in the low variance state and one in the high variance state. The transition probabilities are assumed to be constant. The matrix of transition probabilities $P^{*}$ is a $4 \times 4$ matrix with typical element $p_{i j}^{*}$ for $i, j=1,2,3,4$ and where each column sums to one, $\sum_{i=1}^{4} p_{i j}^{*}=1$ for $j=$ $1,2,3,4$. The unconditional probability of being in state $i$ can be calculated from the estimated transition matrix. Similarly, the smoothed probabilities are defined as in the univariate case. At a given point in time, the economy is said to be in the state which has connected the largest concurrent smoothed probability.

When the states of country 1 and 2 are independent or identical, we can restrict the transition probabilities $p_{i j}^{*}$ to describe these assumptions, cf. Ramchand \& Susmel (1998). As an example we consider the transition probability from state 2 to state $4, p_{42}^{*}$, i.e. going from country 1 in the low variance state and country 2 in the high variance state to both countries being in the high variance state. If the volatility states are independent, then $p_{42}^{*}=p_{12}^{1} p_{22}^{2}$, i.e. the multiple of country 1 changing from state 1 to state 2 , and country 2 staying in state 2 . All elements in $P^{*}$ are given by corresponding multiples of individual transitions probabilities. The assumption of independent volatility states is applied in the interest model of Ang \& Bekaert (2002).

When the variance state of country 1 and 2 are identical, then all elements of $P^{*}$ are zero except for $p_{11}^{*}, p_{14}^{*}, p_{41}^{*}$ and $p_{44}^{*}$. In the empirical analysis, the estimation poses no restrictions on the transition probabilities. Subsequently, the hypotheses of independent states and identical states are tested. The term structure modeling of Christiansen (2004) assumes identical volatility states.

To sum up, we use four different volatility specification in the bivariate model. Below we list in bullet form the volatility equations for model A-D. Model A is the bivariate equivalent to model III, model B to model IV, 
model $\mathrm{C}$ to model V, and model $\mathrm{D}$ to model VI. ${ }^{4}$ Model A has switching level parameters and $\mathrm{ARCH}$ volatilities whereas model B has constant level parameters and SWARCH volatilities. Model C has switching level parameters and constant volatility, whereas model D has constant level parameters and the volatilities are constant in each regime.

- A: Switching-level ARCH model

$$
h_{t}^{i}=\left(\sigma_{t}^{i}\right)^{2}\left(r_{t-1}^{i}\right)^{2 \gamma\left(s_{t}^{i}\right)} \text { where }\left(\sigma_{t}^{i}\right)^{2}=\beta_{0}^{i}+\beta_{1}^{i}\left(\varepsilon_{t-1}^{i}\right)^{2} \text { and } \gamma\left(s_{t}^{i}\right)=\left\{\begin{array}{c}
\gamma_{1}^{i} \\
\gamma_{2}^{i}
\end{array}\right.
$$

- B: Level SWARCH model $h_{t}^{i}=\left(\sigma_{t}^{i}\right)^{2}\left(r_{t-1}^{i}\right)^{2 \gamma}$ where $\left(\sigma_{t}^{i}\right)^{2}=\beta_{0}^{i}\left(s_{t}^{i}\right)+\beta_{1}^{i}\left(\varepsilon_{t-1}^{i}\right)^{2}$ and $\beta_{0}^{i}\left(s_{t}\right)=$ $\left\{\begin{array}{l}\beta_{01}^{i} \\ \beta_{02}^{i}\end{array}\right.$

- C: Switching-level model

$$
h_{t}^{i}=\left(\sigma_{t}^{i}\right)^{2}\left(r_{t-1}^{i}\right)^{2 \gamma\left(s_{t}^{i}\right)} \text { where }\left(\sigma_{t}^{i}\right)^{2}=\beta_{0}^{i} \text { and } \gamma\left(s_{t}^{i}\right)=\left\{\begin{array}{c}
\gamma_{1}^{i} \\
\gamma_{2}^{i}
\end{array}\right.
$$

- D: Level switching-volatility model

$$
h_{t}^{i}=\left(\sigma_{t}^{i}\right)^{2}\left(r_{t-1}^{i}\right)^{2 \gamma} \text { where }\left(\sigma_{t}^{i}\right)^{2}=\beta_{0}^{i}\left(s_{t}^{i}\right) \text { and } \beta_{0}^{i}\left(s_{t}\right)=\left\{\begin{array}{l}
\beta_{01}^{i} \\
\beta_{02}^{i}
\end{array}\right.
$$

We estimate the bivariate model first for the US and the UK short rates and subsequently for the US and German short rates. Firstly, our interest lies in the relation between the short rate volatility state of US and the short rate volatility state of European countries, not the relation between European countries' volatility states. Secondly, an equivalent trivariate model for the US, UK, and German short rates that imposes no restrictions on the transition probabilities have in total $2^{3}=8$ states, so the transition matrix is an $8 \times 8$ matrix which is likely to cause severe estimation problems.

\section{Empirical Results}

In this section we present our empirical results. Firstly, the short-rate data are introduced. Subsequently, in Section 3.2 we show the results from estimating the set of univariate short-rate models country-by-country for the

\footnotetext{
${ }^{4}$ We do not estimate bivariate single regime models. Firstly, in the univariate case they are inferior to two state models. Secondly, they provide no information as to the relation between the countries' volatility states.
} 
US, the UK, and Germany. In Section 3.3 the results from the bivariate models are introduced; first the US-UK results and then the US-German results.

\subsection{Short-Rate Data}

In the empirical analysis we make use of time series of short rates for the US, the UK, and Germany. We measure the US short rate by the 1-month Eurodollar rate, the UK short rate by the 1-month LIBOR rate in Great Britain Pound, and the German short rate by the 1-month Euromark rate. ${ }^{5}$ We use the longest sample period for which data are available for all three countries, namely from January 1975 through December 2004. We use weekly observations and obtain a total of 1565 observations. By using weekly data instead of data of a higher frequency, we overcome at least two problems; on the one hand we diminish the problems arising from differences in trading hours and on the other hand we avoid potential day-of-the-week effects. The short rates are from Wednesdays when available, otherwise they are collected on Thursdays or Tuesdays (in that order). The Eurodollar bid rates are collected from the H.15 release of the Federal Reserve. The LIBOR (offered) rates are obtained from DataStream. The Euromark bid rates are also obtained from DataStream.

Table 1 provides summary statistics for the short rates and the short rate changes. The short rates are measured in percent per annum. The average short rate is largest for the UK (9.23\%), medium for the US (6.75\%), and smallest for Germany (5.25\%). The ordering of the standard deviations also follows this pattern and they fall between $3.70 \%$ (UK) and $2.44 \%$ (Germany). All the short rate series are somewhat right skewed. The US short rates are leptokurtic, the UK short-rates are platykurtic, and the German short rates are close to being mesokurtic. Both the short rates and the squared short rates are highly autocorrelated. The short rates are strongly correlated; the US-UK short rate correlation coefficient equals 0.74, US-Germany 0.59, and UK-Germany 0.66 .

The short rates changes are the explained variables in the subsequent models, and therefore their properties are of major interest. As required, the series of the short-rate changes are stationary according to the augmented

\footnotetext{
${ }^{5}$ After January 1999, i.e. after the launch of the euro, the German Euromark rate is replaced by the euro Eurocurrency rate.
} 
Dickey-Fuller unit root test where the stationary alternative includes a constant and four lags, cf. Dickey \& Fuller (1979). The average short rate changes are close to zero, whereas the standard deviations amount to between $0.24 \%$ (Germany) and $0.38 \%$ (US). The US short rate changes are left skewed, whereas the UK and German series are right skewed. The short rate changes are all highly leptokurtic. The short rate changes show weak negative first order autocorrelation. ${ }^{6}$ As is usual, the squared series of the short rate changes are significantly positively autocorrelated; the first order autocorrelation coefficients are between 0.04 and 0.27 . This suggests using an econometric framework to describe the short rate changes that allows for heteroskedasticity effects. In contrast to the short rates themselves, the short rate changes show only weak correlations; the US-UK short rate changes correlation coefficient equals -0.03, US-Germany -0.06, and UK-Germany 0.04 .

The short rate series show signs of mean reversion, in that the correlation coefficients between the level of the short rate last week and the current short rate change are negative.

\subsection{Country-by-Country Analysis}

We use the Quasi Maximum Likelihood method described in Hamilton (1994, Chapter 22). The estimation is conducted in GAUSS using the constrained maximum likelihood module. The numerical optimization applies a combination of the Berndt-Hall-Hall-Hausman and the Newton-Raphson algorithm. Table 2 contains the results from estimating the univariate models for the short rate, model I-VI outlined in Section 2.1 above. First we present in detail the US results. Subsequently, we compare the UK results to the US results finally we consider the German results.

\subsubsection{US Short Rate Models}

Panel A of Table 2 concerns the US. The findings regarding the mean equation are qualitatively identical across the six volatility specifications. The short rate is mean reverting, i.e. $\widehat{\alpha}_{1}<0$. This corresponds to our a priori expectations: Firstly, the current short rate change is negatively correlated with the level of the short rate last period indicating mean reversion, cf.

\footnotetext{
${ }^{6}$ The first order autocorrelation is only significantly negative for the German short rate changes, not for the US and UK short rate changes.
} 
Section 3.1. Secondly, the existence of mean reversion is in accordance with previous findings, cf. e.g. Chan et al. (1992). Based on an ordinary $t$-test the mean reversion parameter is not significantly negative. ${ }^{7}$ Note, however, that for the null hypothesis of $\alpha_{1}$ equal to zero the process for the short rate changes is non-stationary, so the usual $t$-test is actually not valid.

Model I is the original CKLS level model without regime switching. The level parameter is significantly larger than 1 and significantly smaller than $1 \frac{1}{2} ; \widehat{\gamma}=1.23$. The level parameter is lower than the $1 \frac{1}{2}$ of Chan et al. (1992) most likely because of differences in sample period. Furthermore, the estimated level parameter does not point to any of the well-known short rate models.

Model II is not regime switching, but has both level and heteroskedasticity effects. The level parameter is around unity and insignificantly different here from $(\widehat{\gamma}=1.09)$. A unity level parameter is specified in the short rate model of Brennan \& Schwartz (1980). The level parameter is smaller than for model I, which is typical when introducing heteroskedasticity into the level model, cf. Brenner et al. (1996).

Model III and IV include regime switching, level effects, and ARCH effects. In both models, it is seen that the $\mathrm{ARCH}$ parameter, $\beta_{1}$, is statistically insignificant and small. Thus, it appears that once we introduce state dependent volatility into the short rate model, ARCH effects are superfluous. The remaining parameter estimates are hardly changed by excluding the $\mathrm{ARCH}$ effects $\left(\beta_{1} \equiv 0\right)$. Below we provide further evidence of leaving ARCH effects out of the regime switching models.

Model $\mathrm{V}$ has a state dependent level parameter. In state 1, the level parameter is insignificantly different from $\frac{1}{2}$. State 2 is the high variance state where the level parameter significantly exceeds unity $\left(\widehat{\gamma}_{2}=1.35\right)$, yet is not significantly different from $1 \frac{1}{2}$. This implies that state 1 is compatible with the Cox et al. (1985) square root model, whereas state 2 is compatible with the Cox et al. (1980) volatility specification. Table 3 summarizes the level parameter estimates for model V and VI.

There are no previous findings to compare the estimated level parameters to. The closest we get is Bliss \& Smith (1998) and Dell'Aquila et al. (2003) who apply the CKLS level model with dummy variables to distinguish between the Monetary Experiment and the rest of the sample period.

\footnotetext{
${ }^{7}$ In the following, the default level of significance is $5 \%$.
} 
Our high volatility state covers a much longer fraction of the sample period than the Monetary Experiment, more below, and our high variance state is not deterministic. In Bliss \& Smith (1998) and Dell'Aquila et al. (2003) both $\gamma$ and $\sigma^{2}$ are "state dependent" at the same time, whereas we assume that only one of them is state dependent at a time, to make sure that states are unambiguously low and high volatility states.

The ordinary Wald test is invalid for testing the hypothesis that the level parameters are identical in state 1 and 2, because under the null hypothesis the model is not regime switching and the transition probabilities are not identified. Still, the Wald test can be used as a rough indication of the validity of the hypothesis, cf. e.g. Ramchand \& Susmel (1998). The p-value of the Wald test is far below 1\%, thereby pointing towards using two regimes instead of just one. In the level model without regime switching (model I), the $\gamma$ estimate falls between the $\gamma_{i}$ estimates for state 1 and 2. So neglecting regime switching amounts to averaging the parameter estimates across the states.

In model VI $\sigma_{t}^{2}$ is equal to a different constant in each state. The ordinary Wald test provides informal evidence of significantly different states, the pvalue is far below 1\%. The variance is around 20 times larger in the high variance state than in the low variance state. The level parameter $(\gamma)$ equals 1.26 which is significantly larger than unity and significantly smaller than $1 \frac{1}{2}$, so it is not in accordance with any of the know short rate models. However, it is similar to the parameter estimate in the single regime level model (model I).

In both model $\mathrm{V}$ and VI the low variance state is most common. The unconditional probability of being in state 1 is $58 \%$ and $62 \%$ for model $\mathrm{V}$ and VI, respectively. From the vectors of smoothed probabilities, we conclude that the economy is in state $160 \%$ (model V) and 64\% (model VI) of the time, respectively. This also implies that the low volatility state is not pronouncedly dominant. The correlation between the smoothed state 1 probabilities for model V and VI is 0.91 . The model V and VI indicator functions for being in state 1 have a correlation coefficient of $0.81 .^{8}$ Thus, the two models roughly classify the same periods as being low and high variance states.

\footnotetext{
${ }^{8}$ The state 1 indicator function equals 1 at time $t$ if the contemporaneous smoothed state 1 probability exceeds 0.5 .
} 
Figure 1 shows the smoothed state 1 probabilities for model V. An ideal model classify regimes sharply and has smoothed probabilities that are either close to zero or one. Around $28 \%$ of the smoothed state 1 probabilities are below 0.2 and $43 \%$ are above 0.8 , leaving $29 \%$ blurred observations. The regime classification measure $(R M C 1)$ of Ang \& Bekaert (2002) is close to zero for a perfect model and close to 100 for a model that cannot distinguish between the two states

$$
R M C 1=\frac{400}{T} \sum_{t=1}^{T} \operatorname{prob}\left[s_{t}=1 \mid \Phi_{T}\right] \operatorname{prob}\left[s_{t}=2 \mid \Phi_{T}\right]
$$

where $\operatorname{prob}\left[s_{t}=i \mid \Phi_{T}\right]$ is the time $t$ smoothed state $i$ probability. Table 4 shows the $R C M 1$ s for each of the four regime switching models. The $R C M 1$ is smallest for model VI, for which it equals 29.6. The $R C M 1$ s are smallest for models with regime switching in $\beta_{0}$ compared to models with regime switching in $\gamma$. Overall, the regime classification is fairly good.

The beginnings and endings of the regimes is not as clear-cut as one could wish. The economy is mainly in the high variance regime from the beginning of the sample period in 1975 to the beginning of 1983 . This period includes the NBER business cycle recession that ends in March 1975 and the Monetary Experiment of the Federal Reserve from 1979-1983. The economy is also in the high variance regime around the 1987 stock market crash, in the beginning of the 1990s, which is concurrent with a NBER business cycle recession (July 1990 to March 1991), at the beginning of the 2000s (NBER business cycle recession from March 2001 to November 2001), and at the very end of the sample period. The periods classified as low and high variance states correspond fairly well with our expectations based on previous findings.

Table 5 shows various statistics for the standardized residuals. ${ }^{9}$ Panel A concerns the US. According to the Jarque \& Bera (1980) test for nonnormality (not reported), the standardized residuals for all models are not normally distributed. The main departure from normality occurs via highly leptokurtic residuals. The non normality does not invalidate the models as the estimation is conducted using the quasi ML method. The Lagrange Mul-

\footnotetext{
${ }^{9}$ The standardized residuals are calculated using a weighting scheme based on the ex ante probabilities. This is identical to Gray (1996) as it appears from his shareware GAUSS program used to estimate his Table 2.
} 
tiplier test for no $\mathrm{ARCH}(1)$ effects in the standardized residuals, show no evidence of remaining $\mathrm{ARCH}$ effects in any of the models apart from model I. Also, the squared standardized residuals of model II-VI are not autocorrelated. This further corroborates the conclusions from above that once regime switching is included, it is not necessary to incorporate ARCH effects as well. For model II-VI the first order autocorrelations of the standardized residuals are insignificant. In contrast, the fourth order autocorrelation coefficients are small, negative, and significant based on a $5 \%$ level of significance (although they are insignificant at a $1 \%$ level of significance). Overall, model II-VI appear to be well specified. In contrast, model I standardized residuals show problems of heteroskedasticity and serially correlation both at lag 1 and 4 .

The standardized residuals indicate that the CKLS level model is inappropriate and that there is no gain from including ARCH effects into the regime switching models, i.e. model V and VI are preferred. Yet, we do not have preference of one of those against the other.

Like Bali (2000b) we access the predictive ability of the models by regressing the realized volatility on model forecasted volatility. We compare the explanatory power across models by comparing their $R^{2}$ s. In line with the previous literature, the $R^{2}$ s are not corrected for model complexity. The realized volatility is measured by the absolute short rate changes: $\left|r_{t}-r_{t-1}\right|$ :

$$
\left|r_{t}-r_{t-1}\right|=c_{0}+c_{1} \sqrt{\widehat{h}_{t}}+e_{t}
$$

It is noted that the regression does not consider true out-of-sample predictability, which is similar to Bali $(2000 b)$. Table 6 shows the $R^{2} s$ from these predictive regressions. The $R^{2}$ s are fairly large, above 0.25 . The $R^{2} \mathrm{~s}$ from models without regime switching are smaller than for the models with regime switching. The $R^{2}$ s are largest for the models with level effects and regime switching ( 0.33 for model V and VI). So, we find evidence that including ARCH effects does not increase the predictive power of the model. Thus, also in this respects there is no value added from including $\mathrm{ARCH}$ effects.

In summary, the US short rate shows mean reversion. A model which includes level effects and regime switching is preferred, whereas there is no need for it to include ARCH effects. There is no evidence in favor of using either the model in which the level parameter is regime dependent (model V) 
or the model in which the volatility parameter is regime dependent (model VI). Both specifications capture the essential properties of the US short rate data. This is not unlike the findings of Smith (2002) who uses a short rate model with regime switching stochastic volatility and a state independent level parameter. He finds that it suffices to include regime switching such that (in our notation) $\sigma_{t}^{2}=\left\{\begin{array}{l}\beta_{01} \\ \beta_{02}\end{array}\right.$ or to include stochastic volatility, it is not necessary to include both regime switching and stochastic volatility.

\subsubsection{UK Short Rate Models}

The parameter estimates from the six short rate models for the UK are provided in Panel B of Table 2.

Like the US, the UK short rate shows mean reversion in all model specifications. In the regime switching models the mean reversion parameter $\alpha_{1}$ is significantly negative according to the ordinary $t$-test, cf. the discussion of its deficiencies above.

In neither of the models is the ARCH parameter significant. So, as for the US, including ARCH in the UK short rate model is superfluous once regime switching is included. Therefore, we again focus on model V and VI.

In model $\mathrm{V}$ the level parameter provides regime switching. In the low volatility regime, the level parameter equals 0.91 which is insignificantly different form unity. In the high variance state the level parameter equals 1.68 which is insignificantly different from $1 \frac{1}{2}$. Thus, for the UK short rate the low volatility state is described by the Brennan \& Schwartz (1980) model, cf. Table 3. In contrast, for the US the Cox et al. (1985) square root process is appropriate. In the high variance state, the UK short rate is described by the Cox et al. (1980) model, just like the US short rate. The ordinary Wald test gives a rough indication that the level parameters are significantly different in the two states (the p-value is far below 1\%). As for the US, the UK level parameter in the level model without regime switching (model I) is insignificantly different from unity. Thus, again it falls between the state 1 and state 2 level parameters, i.e. indicating the single regime amounts to averaging across regimes.

In model VI the regime switching occurs via $\sigma^{2}\left(s_{t}\right)$. The variance is about 27 times larger in the high variance state than in the low variance state. So the point estimates of the difference between the low and high vari- 
ance states is more pronounced than for the US. Yet, the ordinary Wald test indicates that the $\beta_{0 i}$ parameters are not significantly different in the two states (the p-value equals $26 \%$ ). We take this as evidence against applying model VI to the UK short rate. The level parameter is just slightly larger than unity and insignificantly so, pointing towards the Brennan \& Schwartz (1980) model. This is equivalent to the $\gamma$ estimate in the single regime level model (model I). For the US the level parameters are larger than unity and smaller than $1 \frac{1}{2}$ in model I and VI.

The economy spends most of its time in the low variance state. The unconditional probability of being in state 1 is $79 \%$ for model $\mathrm{V}$ and $77 \%$ for model VI. According to the smoothed probabilities, the economy spends $82 \%$ (model V) and $81 \%$ (model VI) in the low variance state. So, the dominance of the low variance state is more pronounced than for the US. The two models specify the same periods as low and high variance and the smoothed state 1 probabilities are almost perfectly correlated: The correlation coefficient exceeds 0.99 . Figure 2 shows the smoothed state 1 probability of model V. The economy is mainly in the high variance state in the period 1976-1978. Unlike for the US, there are no official UK business cycle data available to compare to. Table 4 shows the regime classification measures for model III-VI. The $R C M 1$ is smallest for model $\mathrm{V}$ where it equals 23.8. This is unlike for the US where the $R C M 1$ is smallest for model VI. The regime classification is sharper for the UK than the US.

The properties of the standardized residuals for the UK are identical to those of the US, cf. Table 5, Panel B.

The predictability of the six models is assessed by running the regression in equation (19), cf. Table 6. The explanatory power is much lower than for the US, the $R^{2}$ ranges from 0.08 to 0.11 . As for the US, the $R^{2}$ is lowest for the models without regime switching. There is no predictability gain from including ARCH effects into the regime switching models. The $R^{2}$ is almost identical for model V and VI, namely 0.10 and 0.11 , respectively.

Overall, the findings are in favour of short rate models with level effects and regime switching but no $\mathrm{ARCH}$ effect. There is a slight tendency to prefer the specification with state dependent level parameter (model V). 


\subsubsection{German Short Rate Models}

The results from estimating the short rate models for Germany are provided in Table 2, Panel C.

Like the US and UK, all models include mean reversion. The $\mathrm{ARCH}$ parameter, $\beta_{1}$, is only significant in the model without regime switching. So, we confirm for Germany that once regime switching is introduced there is no need for ARCH effects. This points towards models V and VI.

In model $\mathrm{V}$ the level parameter is regime dependent. In the low variance regime, the level parameter is in fact insignificant, whereby the conditional volatility is constant and equals $\sigma^{2}$, just like in Vasicek (1977). In the high variance state, the level parameter is not significantly different from unity, like the Brennan \& Schwartz (1980) model. Thus, the $\widehat{\gamma}_{i}$ s are totally different from the US and UK, cf. Table 3. The ordinary Wald test provides evidence that the level parameters are not identical in the two states, the p-value is far below 1\%. As for the US and the UK, $\widehat{\gamma}$ of the single regime level model falls in between $\widehat{\gamma}_{1}$ and $\widehat{\gamma}_{2}$. It equals 0.87 which is significantly larger than zero and smaller than unity.

In model VI the ordinary Wald test informally indicates no regime switching, the p-value equals $37 \%$. This is similar to the UK but unlike the US. The point estimate of the variance is about 17 times larger in the high variance state than in the low variance state. The difference between the variance across regimes is smaller than for the US and UK. The level parameter is of about the same size as in the single regime level model as for the US and UK.

State 1 is the most common state for model V and VI. The unconditional state 1 probability equals $61 \%$ (model V) and $62 \%$ (model VI). According to the smoothed probabilities, the economy spends $62 \%$ (model V) and $63 \%$ (model VI) of its time in the low variance state. These figures are close to the US but lower than the UK. The appointed low variance periods are close to being identical for models $\mathrm{V}$ and VI: The correlation between the smoothed state 1 probabilities is 0.95 . The smoothed state 1 probabilities for model $\mathrm{V}$ are shown in Figure 3. The economy is mainly in the high variance regime during the first part of the sample period until the beginning of the 1980s. The German reunification in 1990 does not appear to cause the regime switching. There are no official business cycle data available for Germany. Although the division of the sample period into high and low 
volatility periods is not as clear-cut as desirable, the regime classification measures are low, cf. Table 4. The RCM1 is smallest for model $\mathrm{V}$ where it equals 26.0, about the same size as for the UK and much smaller than for the US.

Table 5, Panel C provides information about the standardized residuals. For models I to IV there are no differences to the US, whereas for model $\mathrm{V}$ there is evidence of unaccounted serial correlation and heteroskedasticity. For model VI there is evidence of unaccounted serial correlation.

The predictability of the models measured by the $R^{2} \mathrm{~s}$ obtained from regression (19) are in between the US and UK for models IV and V. The $R^{2} \mathrm{~s}$ are largest for model $\mathrm{V}$ and VI and amount to 0.13 and 0,14 , respectively.

Overall, we take our results as providing evidence for the short rate model with level effects and regime switching but no ARCH effects. The results provide no preference for regime switching in the level parameter or in $\sigma_{t}^{2}$. This confirms the US and UK results.

\subsection{Bivariate Analysis}

The estimation of the bivariate models is conducted similar to the univariate models. Firstly, the US-UK results are examined at some length, and subsequently the US-German results are discussed briefly.

\subsubsection{US-UK Results}

Panel A of Table 7 shows the parameter estimates for the bivariate models for the US-UK short rate changes. The estimated correlation coefficients $(\rho)$ are small, negative, and insignificant, between -0.015 and -0.038 . This is perhaps not surprising because the raw correlation between the US and UK short rate changes amounts to -0.03 , cf. Section 3.1.

As in the univariate models, the ARCH parameter, $\beta_{1}^{i}$, is insignificant in model $\mathrm{A}$ and $\mathrm{B}$. So, we prefer model $\mathrm{C}$ and $\mathrm{D}$ with regime switching and level effects, but no ARCH effects. This is similar to the univariate results. The parameter estimates in both model $\mathrm{C}$ and $\mathrm{D}$ correspond to the univariate equivalents.

For model C, the ordinary Wald test for the null hypothesis of $\gamma_{1}^{1}=$ $\gamma_{2}^{1} \wedge \gamma_{1}^{2}=\gamma_{2}^{2}$ provides an informal indication of the validity of a one-regime model. For model $\mathrm{D}$ the null hypothesis is $\beta_{01}^{1}=\beta_{02}^{1} \wedge \beta_{01}^{2}=\beta_{02}^{2}$. Notice, that under both null hypotheses, the transition probability matrix $P^{*}$, is not 
defined, cf. the discussion in Section 3.2.1 above. The resulting p-values are far below $1 \%$ suggesting that one-regime models are inadequate.

For clarity, Table 7 reports the unconditional state probabilities not the estimated $4 \times 4$ transition probability matrix $P^{*}$. The ordering of the unconditional probabilities is identical for model $\mathrm{C}$ and $\mathrm{D}$. The unconditional probabilities of the low-low volatility state $\left(s_{t}^{*}=1\right)$ exceed $50 \%$. The second most likely situation is the US high-UK low volatility state $\left(s^{*}=3\right)$, followed by both countries being in the high variance state $\left(s_{t}^{*}=4\right)$. The least likely is the US low-UK high volatility state $\left(s^{*}=2\right)$. For model $\mathrm{C}$, the unconditional probability of the US being in the low variance state (sum of $s^{*}=1$ and $s^{*}=2$ probabilities) equals $58 \%$ (same as in univariate model). The probability of the UK being in the low variance state $\left(s^{*}=1\right.$ and $s^{*}=3$ ) equals $79 \%$ again equivalent to the univariate case. In model $\mathrm{D}$, the unconditional probability of the US being in state 1 is slightly larger than in the univariate model and unaltered for the UK.

Based on the smoothed probabilities for model C (model D), the economy spends $54 \%(56 \%)$ of the time in the low-low volatility state $\left(s^{*}=1\right), 29 \%$ $(25 \%)$ in the US low-UK high volatility state $\left(s^{*}=3\right), 11 \%(8 \%)$ in the highhigh volatility state $\left(s^{*}=4\right)$, and $6 \%(10 \%)$ in the US low-UK high volatility state $\left(s^{*}=2\right)$. Model by model, the bivariate smoothed probabilities for the US being in the low volatility state are almost identical to the US univariate smoothed probabilities of the low volatility state. The same applies to the UK. The correlations are between $96 \%$ and $98 \%$.

The regime classification measure for two states of Ang \& Bekaert (2002) in equation (18) is extended to multiple states in Baele (forthcoming). For four states it reads:

$$
R C M 2=100\left(1-\frac{4}{3} \frac{1}{T} \sum_{t=1}^{T} \sum_{j=1}^{4}\left(\operatorname{prob}\left[s_{t}^{*}=j \mid \Phi_{t}\right]-\frac{1}{4}\right)^{2}\right)
$$

The $R C M 2$ lies between 0 (perfect) and 100 (worst). The regime classification measures are shown in Table 9 . The RCM2 is smallest for the non-ARCH models, and for those it is slightly smaller for model D than for model C; 33.8 compared to 34.5 . This is equivalent to the univariate US results, but opposite the univariate UK result.

In order to test if the volatility states of the US and UK are independent, we estimate model $\mathrm{C}$ including appropriate restrictions on the transition 
matrix, cf. the discussion in the last part of Section 2.2. We use a Likelihood Ratio test to test the null hypothesis of independent states, cf. Susmel (2000) and Baele (forthcoming). The test statistic is $\chi^{2}$ distributed where the degrees of freedom equal the difference in the number of parameters in the restricted and unrestricted model. ${ }^{10}$ The $L R$ test is also used to test for identical states. Here, the restricted model with identical states is actually not nested in the unrestricted model, still the ordinary $\chi^{2}$ distribution is applied, cf. Baele (forthcoming). The same set of $L R$ tests are applied to model D. For both model C and D we strongly reject that the US and UK volatility states are independent, implying that the volatility state of one country influences the volatility state of the other country and vice versa. The US and UK volatility states are significantly not identical either, so the economies are not always in the same volatility state. The $L R$ p-values are all far below $1 \%$. Thus, the dependence of the US and UK volatility states is somewhere between the two extreme cases and it makes sense to take account of the interdependence in empirical work, unlike e.g. Ang \& Bekaert (2002) and Christiansen (2004).

The standardized residuals imply that the models are fairly well specified, cf. Table 9. The cross multiplied standardized residuals are not serially correlated, which indicates that there is no unaccounted heteroskedasticity in the covariances.

To compare the predictive power of the models we conduct similar predictive regressions as in equation (19); a regression for the US short rate and another regression for the UK short rate. In a third covariance regression the explained variable is $\left(\left|r_{t}^{1}-r_{t-1}^{1}\right|\left|r_{t}^{2}-r_{t-1}^{2}\right|\right)$ and the explanatory variable is the estimated covariance $\left(\widehat{h_{t}^{12}}\right)$. The predictive power is much larger for the non-ARCH models (model $\mathrm{C}$ and $\mathrm{D}$ ) than for the ARCH models (model A and $\mathrm{B}$ ). The $R^{2} \mathrm{~s}$ are slightly larger for model $\mathrm{D}$ than $\mathrm{C}$. The $R^{2} \mathrm{~s}$ for the volatility regressions are of about the same size as in the univariate case. The $R^{2}$ s from the covariance regressions fall between the US and UK $R^{2}$ s.

To sum up, the bivariate models provide similar information as the univariate models as to the preferred short rate volatility specification. From the bivariate setting we learn about the coincidence and dependence of the US and UK volatility states, namely that the US and UK volatility states are neither independent nor identical.

\footnotetext{
${ }^{10}$ Elements of $P^{*}$ with zero point estimates do not count to the number of parameters.
} 


\subsubsection{US-German Results}

The parameter estimates for the US-German estimation are shown in Panel B of Table 7. As above, the parameter estimates are almost identical to those from the univariate regressions and the correlation coefficient $(\rho)$ is small, negative, and insignificant. Again, the non-ARCH models are superior.

According to the $R C M 2$ the preferred specification is model $\mathrm{C}$, cf. Table 8 which is similar to German univariate results and opposite US univariate results. In contrast, the standardized residuals point towards model D, cf. Table 9 , similar to the univariate German results. The predictive regressions do not select model C above model D, cf. Table 10.

According to the smoothed probabilities of model C (model D), the economy spends $57 \%$ (52\%) in the low-low volatility state, $18 \%$ (17\%) in the highhigh volatility state, $13 \%$ (16\%) in the US high-German low volatility state, and $12 \%(14 \%)$ in the US low-German high volatility state. The smoothed probabilities for the US low volatility (states $s^{*}=1$ and $s^{*}=2$ ) and the German low volatility (states $s^{*}=1$ and $s^{*}=3$ ) are strongly correlated with the univariate equivalents, the correlation coefficients are between $91 \%$ and $96 \%$. So, the bivariate models classify the same periods as low volatility periods and high volatility periods as the univariate models. The ordinary Wald tests provide evidence against non-switching models.

The $L R$ test for identical US and German volatility states is clearly rejected for both model $\mathrm{C}$ and D. Similarly, the $L R$ test rejects that the US and German volatility states are independent. This implies, that the dependence between the US volatility state and the German volatility state falls somewhere between these two extreme cases. The conclusions regarding volatility state interdependence are identical to the US-UK results.

\section{Conclusion}

This paper investigates models for the short rates of the US, the UK, and Germany. Firstly, we analyze one country at a time. We extend the CKLS short rate model (where the conditional volatility is proportional to the $\gamma$ th power of the level of the short rate) to include both heteroskedasticity effects and regime switching volatility. The regime switching either occur in the level parameter or in the constant in the ARCH specification. For each country we estimate six different versions of the short rate model. We show 
that once the short rate model includes regime switching and level effects there are no further gains from including ARCH effects as well. This conclusion is based on the parameter estimates, the regime classification measure, the properties of the residuals, and predictive regressions. Moreover, the inclusion of regime switching is essential. Furthermore, it is of secondary importance whether the regime switching occurs in the level parameter or in the $\mathrm{ARCH}$ parameter. When the level parameter is state independent it is an average of the level parameters in the low and high variance states. When the regime switching occur via the $\mathrm{ARCH}$ parameter the volatility is several times higher in the high variance state than in the low variance state. The estimated level parameters are very different across countries. The estimated level parameters are compared to various popular short rate models.

We also estimate equivalent bivariate models for the US-UK short rates as well as for the US-German short rates. The findings regarding the short rate volatilities are unaltered compared to the univariate models. Most importantly, we find that the volatility states of the US and UK are not independent. Moreover, the US and UK economies are not in the same volatility state at the same time. Equivalent, the short rate volatility states of the US and Germany are not independent and not identical.

The papers highlights that it is important to account for the fact that the volatility states of short rates of different countries are neither independent nor identical. In future research it would be interesting to investigate in more detail the severity of applying these assumptions which are applied because they simplify the estimation. 


\section{References}

Andersen, T. G. \& Lund, J. (1997), 'Estimating Continuous-Time Stochastic Volatility Models of the Short-Term Interest Rate', Journal of Econometrics 77, 343-377.

Ang, A. \& Bekaert, G. (2002), 'Regime Switching in Interest Rates', Journal of Business 85 Economic Statistics 20(2), 163-182.

Baele, L. (forthcoming), 'Volatility Spillover Effects in European Equity Markets', Journal of Financial and Quantitative Analysis .

Bali, T. G. (2000a), 'Modeling the Conditional Mean and Variance of the Short Rate Using Diffusion, GARCH, and Moving Average Models', Journal of Futures Markets 20(8), 717-751.

Bali, T. G. (2000b), 'Testing the Empirical Performance of Stochastic Volatility Models of the Short-Term Interest Rate', Journal of Financial and Quantitative Analysis 35(2), 191-215.

Bliss, R. R. \& Smith, D. C. (1998), 'The Elasticity of Interest Rate Volatility: Chan, Karolyi, Longstaff, and Sanders Revisited', Journal of Risk 1(1), 21-246.

Bollerslev, T. (1986), 'Generalized Autoregressive Conditional Heteroskedasticity', Journal of Econometrics 31, 307-327.

Bollerslev, T. (1990), 'Modeling the Coherence in Short-Run Nominal Exchange Rates', Review of Economics and Statistics 72, 498-505.

Bollerslev, T. \& Wooldridge, J. M. (1992), 'Quasimaximum Likelihood Estimation and Inference in Dynamic Models with Time Varying Covariances', Econometric Reviews 11, 143-172.

Brennan, M. J. \& Schwartz, E. S. (1980), 'Analyzing Convertible Bonds', Journal of Financial and Quantitative Analysis 17, 75-100.

Brenner, R. J., Harjes, R. H. \& Kroner, K. F. (1996), 'Another Look at Models of the Short-Term Interest Rate', Journal of Financial and Quantitative Analysis 31(1), 85-107. 
Cai, J. (1994), 'A Markov Model of Switching-Regime ARCH', Journal of Business \& Economic Statistics 12(3), 309-316.

Chan, K. C., Karolyi, A., Longstaff, F. A. \& Sanders, A. B. (1992), 'An Empirical Comparison of Alternative Models of the Short-Term Interest Rate', Journal of Finance 47(3), 1209-1227.

Christiansen, C. (2004), 'Regime Switching in the Yield Curve', Journal of Futures Markets 24(4), 315-336.

Christiansen, C. (2005), 'Multivariate Term Structure Models with Level and Heteroskedasticity Effects', Journal of Banking $\mathcal{G}_{3}$ Finance 29, 1037-1057.

Cox, J. C., Ingersoll, J. E. \& Ross, S. A. (1980), 'An Analysis of Variable Rate Loan Contracts', Journal of Finance 35, 389-403.

Cox, J. C., Ingersoll, J. E. \& Ross, S. A. (1985), 'A Theory of the Term Structure of Interest Rates', Econometrica 53, 385-407.

Dahlquist, M. \& Gray, S. F. (2000), 'Regime-Switching and Interest Rates in the European Monetary System', Journal of International Economics 50, 399-419.

Dell'Aquila, R., Ronchetti, E. \& Trojani, F. (2003), 'Robust GMM Analysis of Models for the Short Rate Process', Journal of Empirical Finance 10, 373-397.

Dewachter, H. (1996), 'Modeling Interest Rate Volatility: Regime Switchces and Level Links', Weltwirtschaftliches Archiv 132(2), 236-258.

Dickey, D. A. \& Fuller, W. A. (1979), 'Distribution of the Estimators for Autoregressive Time Series with a Unit Root', Journal of the American Statistical Association 74, 427-431.

Durham, G. B. (forthcoming), 'Likelihood-Based Specification Analysis of Continuous-Time Models of the Short-Term Interest Rate', Journal of Financial Economics .

Engle, R. F. (1982), 'Autoregressive Conditional Heteroskedasticity with Estimates of the Variance of United Kingdom Inflation', Econometrica 50, 987-1007. 
Ferreira, M. A. (forthcoming), 'Forecasting the Comovements of Spot Interest Rates', Journal of International Money 83 Finance.

Gray, S. F. (1996), 'Modeling the Conditional Distribution of Interest Rates as a Regime-Switching Process', Journal of Financial Economics 42, 27-62.

Hamilton, J. D. (1994), Time Series Analysis, Princeton University Press.

Hamilton, J. D. \& Susmel, R. (1994), 'Autoregressive Conditional Heteroskedasticity and Changes in Regime', Journal of Econometrics 64, 307-333.

Jarque, C. M. \& Bera, A. K. (1980), 'Efficient Tests for Normality', Economics Letters 6, 255-259.

Koedjik, K. G., Nisssen, F. G. J. A., Schotman, P. C. \& Wolff, C. C. P. (1997), 'The Dynamics of Short-Term Interest Rate Volatility Reconsidered', European Finance Review 1, 105-130.

Laumoreux, C. G. \& Lastrapes, W. D. (1990), 'Persistence in Variance, Structural Change, and the GARCH Model', Journal of Business $\&$ Economic Statistics 8(2), 225-234.

Longstaff, F. A. \& Schwartz, E. S. (1992), 'Interest Rate Volatility and the Term Structure: A Two-Factor General Equilibrium Model', Journal of Finance 47(4), 1259-1282.

Ramchand, L. \& Susmel, R. (1998), 'Volatility and Cross Correlation across Major Stock Markets', Journal of Empirical Finance 5, 397-416.

Smith, D. R. (2002), 'Markov-Switching and Stochastic Volatility Diffusion Models of Short-Term Interest Rates', Journal of Business $\& 3$ Economic Statistics 20(2), 183-197.

Susmel, R. (2000), 'Switching Volatility in International Equity Markets', International Journal of Finance 83 Economics 5, 265-283.

Vasicek, O. (1977), 'An Equilibrium Characterization of the Term Structure', Journal of Financial Economics 5, 177-188. 
Table 1: Summary Statistics

\begin{tabular}{l|rr|rr|rr} 
& \multicolumn{2}{|c|}{ US } & \multicolumn{2}{c|}{ UK } & \multicolumn{2}{c}{ Germany } \\
& \multicolumn{1}{|c|}{$r$} & \multicolumn{1}{c|}{$\Delta r$} & \multicolumn{1}{c}{$\Delta r$} & \multicolumn{1}{c}{$\Delta$} & \multicolumn{1}{c}{$\Delta r$} \\
\hline Mean & 6.75 & -0.005 & 9.23 & -0.004 & 5.25 & -0.003 \\
Std dev & 3.59 & 0.38 & 3.7 & 0.34 & 2.44 & 0.24 \\
Skewness & 0.99 & -0.22 & 0.34 & 1.44 & 0.94 & 2.71 \\
Kurtosis & 4.47 & 24.38 & 2.09 & 20.76 & 3.07 & 66.43 \\
AC, 1 & 0.994 & -0.018 & 0.995 & -0.039 & 0.995 & -0.106 \\
AC, 4 & 0.973 & -0.016 & 0.981 & 0.069 & 0.982 & -0.005 \\
AC, sq, 1 & 0.971 & 0.265 & 0.983 & 0.148 & 0.975 & 0.038 \\
AC, sq, 4 & 0.869 & 0.205 & 0.942 & 0.058 & 0.934 & 0.022 \\
cor $\left(r_{t-1} \Delta r_{t}\right)$ & \multicolumn{2}{|c|}{-0.051} & \multicolumn{2}{|c|}{-0.042} & \multicolumn{2}{|c}{-0.043}
\end{tabular}

Notes: The table reports the summary statistics for the US 1-month Eurodollar rate, the UK 1-month LIBOR, and the German 1-month Euromark rate. The interest rates are measured in percent per annum. The weekly (Wednesdays) data cover the period 1975-2004. For each country the first column concerns the short rate $(r)$, and the second column the short rate changes $(\Delta r)$. The following statistics are reported: Mean, standard deviation, skewness, kurtosis, autocorrelation (order 1 and 4), autocorrelation of the squared series (order 1 and 4), and the correlation between the short rate last week and the current short rate changes. 
Table 2: Univariate Results

Panel A: US

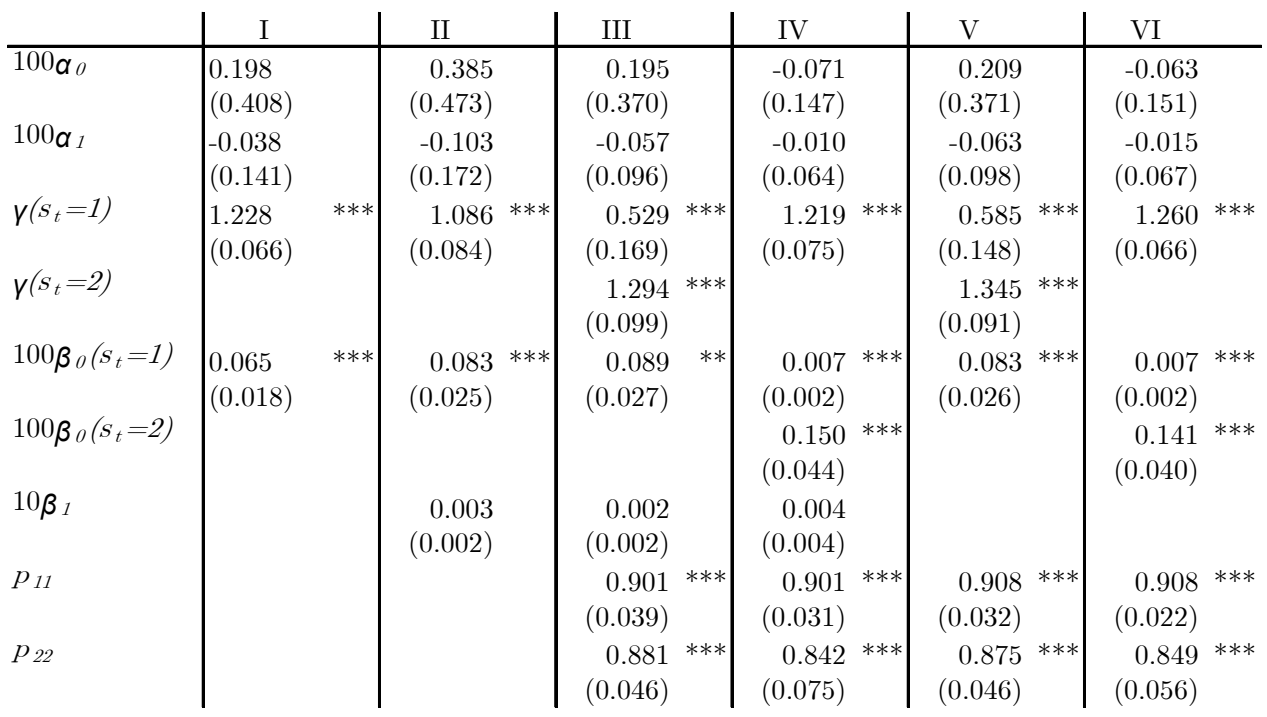

Panel B: UK

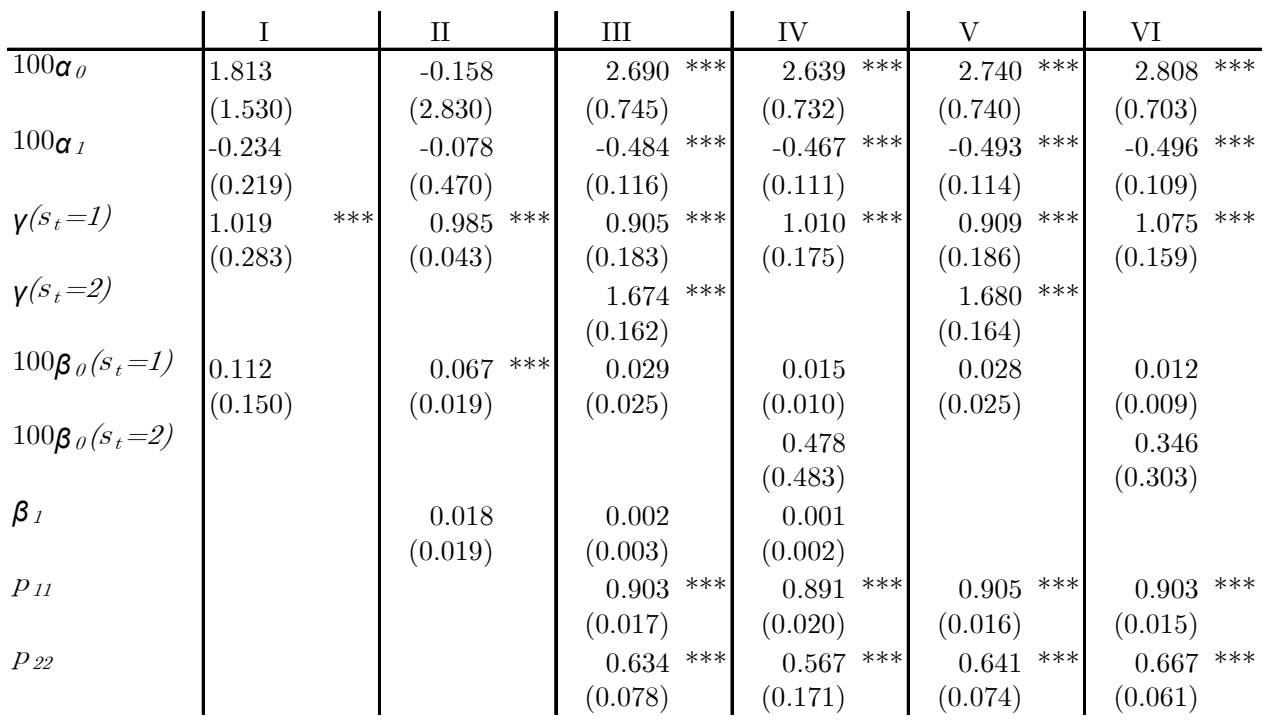


Panel C: Germany

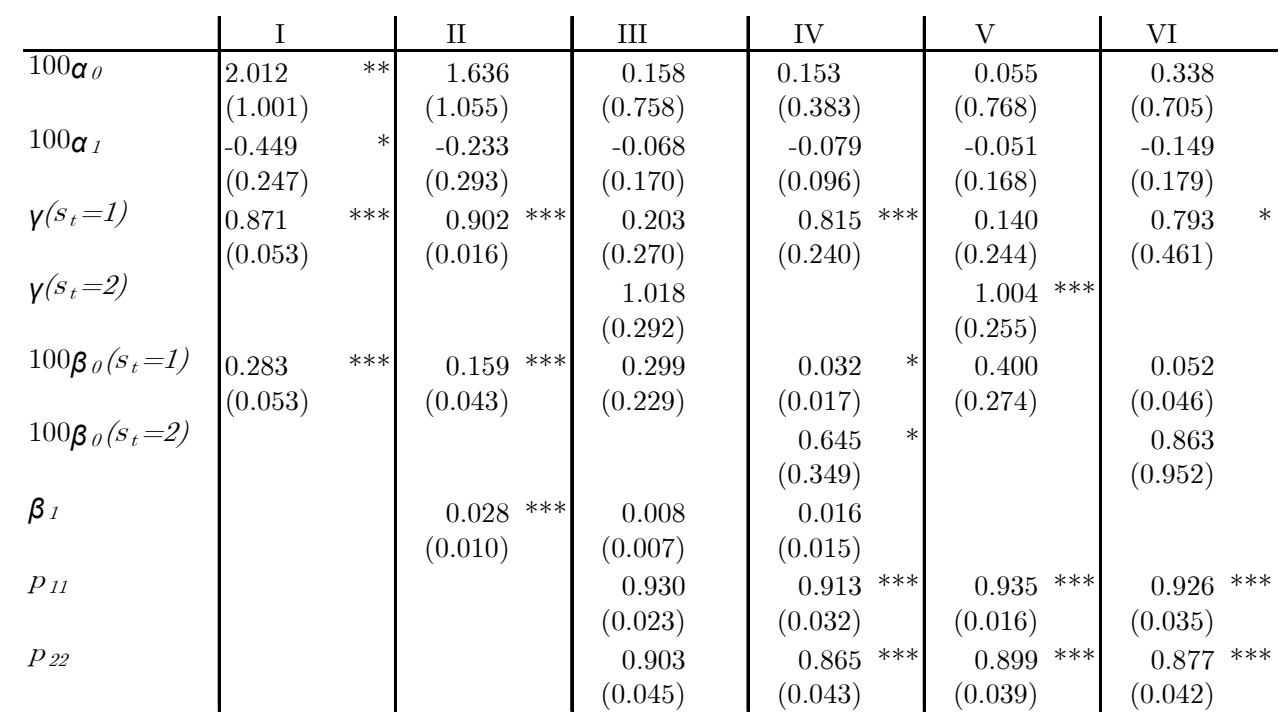

Notes: The table shows the parameter estimates from the univariate model for the short rate changes for the US, UK, and Germany: $r_{t}-r_{t-1}=\alpha_{0}+\alpha_{1} r_{t-1}+\epsilon_{t}$ where the conditional variance of the residual is given by: $h_{t}=\sigma_{t}^{2} r_{t-1}^{2 \gamma\left(s_{t}\right)}$ where $\sigma_{t}^{2}=\beta_{0}\left(s_{t}\right)+\beta_{1} \varepsilon_{t-1}^{2}$. Bollerslev \& Wooldridge (1992) robust standard errors in parentheses. Model I: Level. Model II: Level ARCH. Model III: Switching-Level ARCH with $\beta_{01}=\beta_{02}$. Model IV: Level SWARCH with $\gamma_{1}=\gamma_{2}$. Model V: Switching-Level with $\beta_{01}=\beta_{02}$. Model VI: Level switching-volatility with $\gamma_{1}=\gamma_{2} .{ }^{*}, * *, * * *$ indicates that the parameter is significant at $10 \%, 5 \%$, and $1 \%$ level of significance, respectively. 
Table 3: Corresponding Short-Rate Models

\begin{tabular}{|c|c|c|c|}
\hline & \multicolumn{2}{|c|}{ Model V } & \multirow[t]{2}{*}{ Model VI } \\
\hline & State 1 & State 2 & \\
\hline \multirow[t]{2}{*}{ US } & $\gamma=\frac{1}{2}$ & $\gamma=1 \frac{1}{2}$ & $\gamma \in\left(1 ; 1 \frac{1}{2}\right)$ \\
\hline & Cox et al. (1985) & Cox et al. (1980) & NA \\
\hline \multirow[t]{2}{*}{ UK } & $\gamma=1$ & $\gamma=1 \frac{1}{2}$ & $\gamma=1$ \\
\hline & Brennan \& Schwartz (1980) & Cox et al. (1980) & Brennan \& Schwartz (1980) \\
\hline \multirow[t]{2}{*}{ Germany } & $\gamma=0$ & $\gamma=1$ & $\gamma=\frac{1}{2}$ \\
\hline & Vasicek (1977) & Brennan \& Schwartz (1980) & Cox et al. (1985) \\
\hline
\end{tabular}

Notes: The table summarizes the estimated level parameters and the corresponding short rate models. Model V: Switching-Level with $\beta_{01}=\beta_{02}$. Model VI: Level switchingvolatility with $\gamma_{1}=\gamma_{2}$. 
Table 4: Regime Classification Measures - Univariate Models

\begin{tabular}{l|rrrr} 
& \multicolumn{1}{|c}{ III } & \multicolumn{1}{c}{ IV } & \multicolumn{2}{c}{ V } \\
\hline US & 36.6 & 32.9 & 36.1 & 29.6 \\
UK & 24.0 & 27.5 & 23.8 & 24.5 \\
Germany & 28.5 & 34.3 & 26.0 & 28.1
\end{tabular}

Notes: The table reports the regime classification measure (RCM1) of Ang \& Bekaert (2002) for the univariate model for the short rate changes for the US, UK, and Germany: Model III: Switching-Level ARCH with $\beta_{01}=\beta_{02}$. Model IV: Level SWARCH with $\gamma_{1}=\gamma_{2}$. Model V: Switching-Level with $\beta_{01}=\beta_{02}$. Model VI: Level switchingvolatility with $\gamma_{1}=\gamma_{2}$. 
Table 5: Standardized Residuals - Univariate Models

Panel A: US

\begin{tabular}{|c|c|c|c|c|c|c|c|}
\hline & I & II & III & IV & $\mathrm{V}$ & VI & \\
\hline Skewness & 0.42 & 0.97 & 0.60 & -0.20 & 0.57 & -0.24 & \\
\hline Kurtosis & 17.13 & 18.23 & 25.81 & 25.13 & 26.06 & 26.24 & \\
\hline $\mathrm{ARCH}(1)$ & 48.40 & 0.56 & 0.51 & 0.02 & 1.34 & 0.41 & \\
\hline $\mathrm{AC}, 1$ & $-0.057 * *$ & -0.038 & -0.031 & -0.026 & -0.032 & -0.028 & \\
\hline $\mathrm{AC}, 4$ & $-0.013 * * *$ & $-0.013 \quad * *$ & $-0.016 \quad * *$ & $-0.021 \quad * *$ & -0.018 & -0.021 & $* *$ \\
\hline $\mathrm{AC}, \mathrm{sq}, 1$ & 0.176 *** & 0.019 & 0.018 & 0.004 & 0.029 & 0.016 & \\
\hline $\mathrm{AC}, \mathrm{sq}, 4$ & 0.049 *** & 0.049 & 0.019 & 0.015 & 0.019 & 0.014 & \\
\hline
\end{tabular}

\section{Panel B: UK}

\begin{tabular}{|c|c|c|c|c|c|c|}
\hline & I & II & III & IV & $\mathrm{V}$ & VI \\
\hline Skewness & 3.36 & 3.31 & 3.42 & 2.89 & 3.39 & 2.80 \\
\hline Kurtosis & 45.59 & 32.30 & 36.62 & 24.56 & 36.33 & 24.77 \\
\hline $\mathrm{ARCH}(1)$ & 7.45 *** & 0.03 & 0.45 & 0.00 & 0.75 & 0.28 \\
\hline $\mathrm{AC}, 1$ & -0.036 & 0.008 & -0.013 & -0.01 & -0.017 & -0.014 \\
\hline $\mathrm{AC}, 4$ & 0.076 *** & $0.0074 \quad * *$ & $0.085 * * *$ & $0.093 * * *$ & 0.086 *** & $0.094 * * *$ \\
\hline $\mathrm{AC}, \mathrm{sq}, 1$ & $0.069 * * *$ & -0.004 & 0.017 & -0.001 & 0.022 & 0.013 \\
\hline $\mathrm{AC}, \mathrm{sq}, 4$ & $0.023 * *$ & 0.048 & 0.034 & 0.06 & 0.034 & 0.055 \\
\hline
\end{tabular}

Panel C: Germany

\begin{tabular}{|c|c|c|c|c|c|c|}
\hline & I & II & III & IV & $\mathrm{V}$ & VI \\
\hline Skewness & 0.92 & 1.24 & 0.52 & 2.20 & 0.58 & 1.69 \\
\hline Kurtosis & 23.15 & 30.7 & 14.86 & 43.52 & 14.56 & 30.01 \\
\hline $\operatorname{ARCH}(1)$ & 42.57 *** & 0.03 & 0.07 & 0.05 & 7.86 *** & 0.64 \\
\hline $\mathrm{AC}, 1$ & $-0.092 * * *$ & $-0.051 * *$ & $-0.052 \quad * *$ & $-0.053 \quad * *$ & $-0.067 * * *$ & $-0.070 * * *$ \\
\hline $\mathrm{AC}, 4$ & $0.006 * * *$ & 0.014 & 0.014 & 0.011 & $0.013 \quad * *$ & $0.011 \quad * *$ \\
\hline $\mathrm{AC}, \mathrm{sq}, 1$ & $0.165 * * *$ & -0.005 & 0.007 & -0.005 & $0.071 * * *$ & 0.020 \\
\hline $\mathrm{AC}, \mathrm{sq}, 4$ & $0.048 * * *$ & 0.012 & 0.010 & -0.000 & $0.018 * * *$ & 0.004 \\
\hline
\end{tabular}

Notes: The table reports various statistics for the standardized residuals from the univariate model for the short rate changes for the US, UK, and Germany: Model I: Level. Model II: Level ARCH. Model III: Switching-Level ARCH with $\beta_{01}=\beta_{02}$. Model IV: Level SWARCH with $\gamma_{1}=\gamma_{2}$. Model V: Switching-Level with $\beta_{01}=\beta_{02}$. Model VI: Level switching-volatility with $\gamma_{1}=\gamma_{2}$. The following statistics are reported: Skewness, Kurtosis, LM test statistic for ARCH(1), autocorrelation (order 1 and 4), and autocorrelation for squared standardized residuals (order 1 and 4). (Except for the skewness and kurtosis $*^{*},{ }^{*}, *^{* *}$ indicates significance at $10 \%, 5 \%$, and $1 \%$ level of significance. 
Table 6: Predictive Power - Univariate Models

\begin{tabular}{l|cccccc} 
& I & II & III & IV & V & VI \\
\hline US & 0.29 & 0.25 & 0.33 & 0.31 & 0.33 & 0.33 \\
UK & 0.08 & 0.08 & 0.10 & 0.11 & 0.10 & 0.11 \\
Germany & 0.05 & 0.05 & 0.08 & 0.08 & 0.13 & 0.14
\end{tabular}

Notes: For the univariate models for the US, UK, and Germany, the table reports the $R^{2} \mathrm{~s}$ from regressing the absolute short rate change $\left(\left|r_{t}-r_{t-1}\right|\right)$ on its estimated volatility $\left(\sqrt{\widehat{h_{t}}}\right)$. Model I: Level. Model II: Level ARCH. Model III: Switching-Level ARCH with $\beta_{01}=\beta_{02}$. Model IV: Level SWARCH with $\gamma_{1}=\gamma_{2}$. Model V: Switching-Level with $\beta_{01}=\beta_{02}$. Model VI: Level switching-volatility with $\gamma_{1}=\gamma_{2}$. 
Table 7: Bivariate Results

Panel A: US-UK

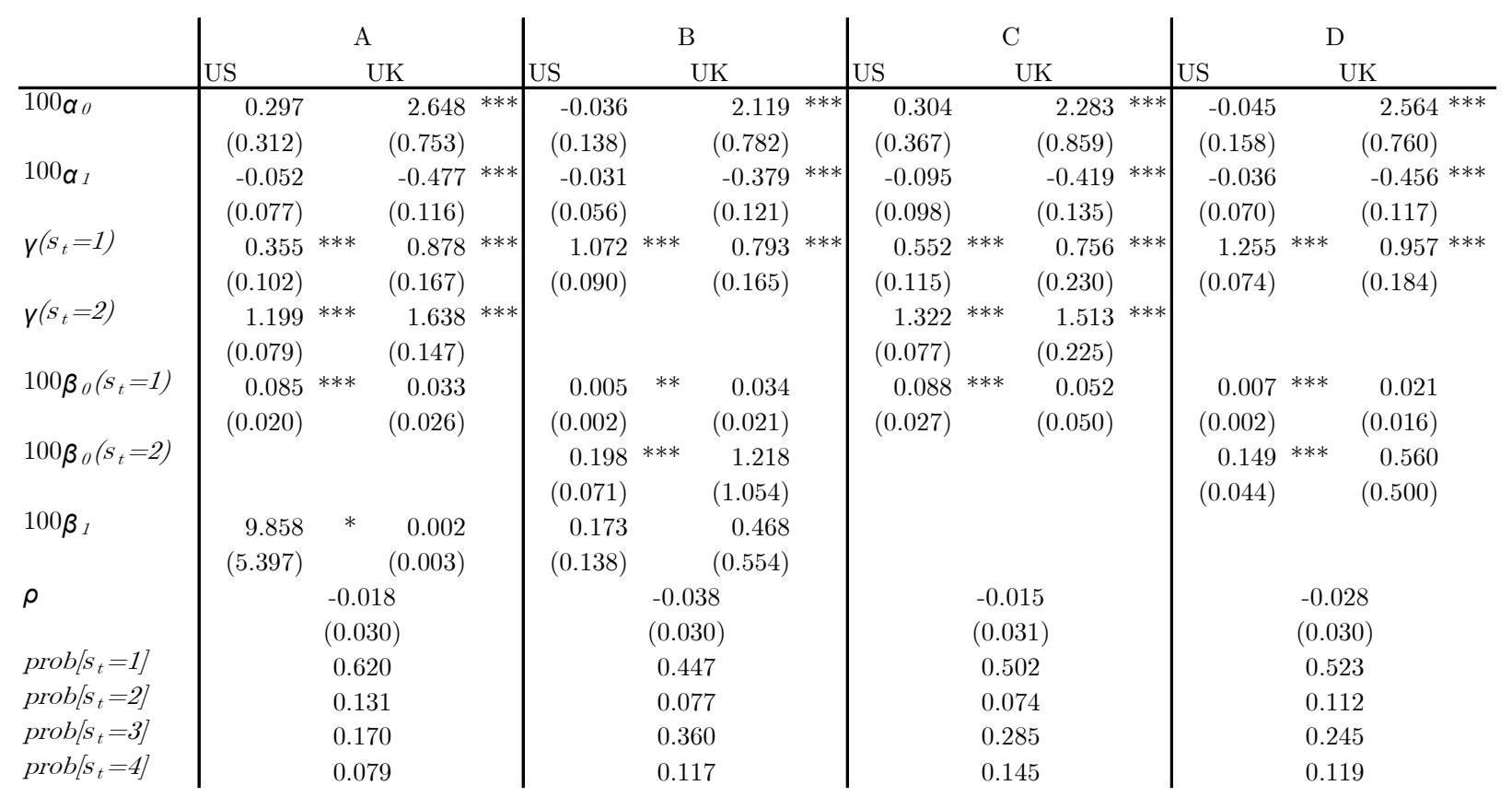


Panel B: US-Germany

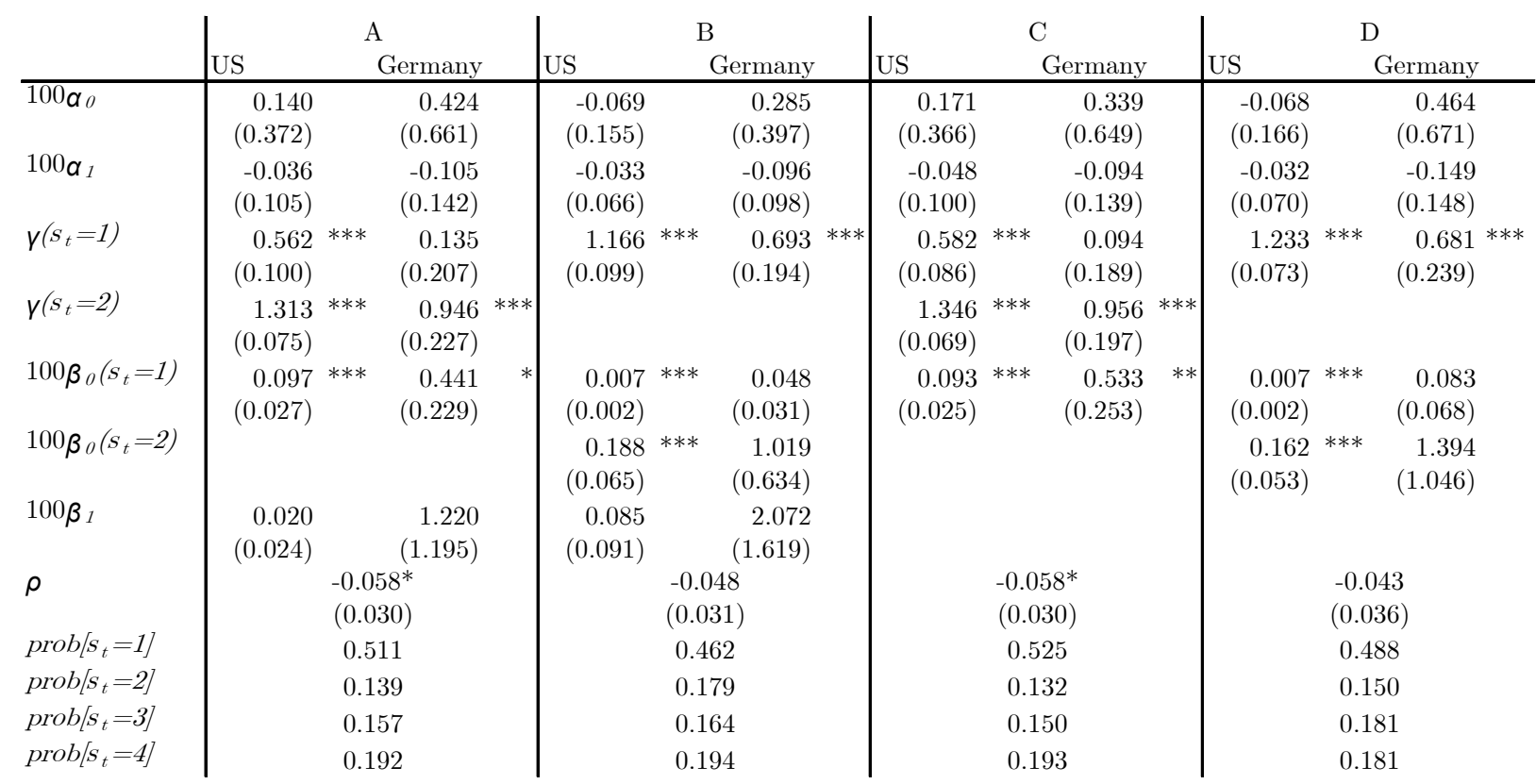

Notes: The table shows the parameter estimates from the bivariate model for the short rate changes for the US-UK and US-Germany: $r_{t}^{i}-r_{t-1}^{i}=\alpha_{0}^{i}+\alpha_{1}^{i} r_{t-1}+\epsilon_{t}$ for $i=$ 1,2 where the conditional variance of the residual is given by: $h_{t}^{i}=\left(\sigma_{t}^{i}\right)^{2}\left(r_{t-1}^{i}\right)^{2 \gamma^{i}\left(s_{t}\right)}$ where $\left(\sigma_{t}^{i}\right)^{2}=\beta_{0}^{i}\left(s_{t}^{i}\right)+\beta_{1}^{i}\left(\varepsilon_{t-1}^{i}\right)^{i}$ and the conditional covariance is given by: $h_{t}^{12}=$ $\rho \sqrt{h_{t}^{1} h_{t}^{2}}$. Bollerslev \& Wooldridge (1992) robust standard errors in parentheses. Model A: Switching-Level ARCH with $\beta_{01}^{i}=\beta_{02}^{i}$. Model B: Level SWARCH with $\gamma_{1}^{i}=$ $\gamma_{2}^{i}$. Model C: Switching-Level with $\beta_{01}^{i}=\beta_{02}^{i}$. Model D: Level switching-volatility with $\gamma_{1}^{i}=\gamma_{2}^{i} . * * *, * * *$ indicates that the parameter is significant at $10 \%, 5 \%$, and $1 \%$ level of significance, respectively. 
Table 8: Regime Classification Measure - Bivariate Models

\begin{tabular}{l|rrrr} 
& \multicolumn{1}{|c}{ A } & \multicolumn{1}{c}{ B } & \multicolumn{1}{c}{ C } & \multicolumn{1}{c}{ D } \\
\hline US-UK & 35.5 & 40.2 & 34.5 & 33.8 \\
US-Germany & 37.5 & 43.1 & 34.9 & 36.3
\end{tabular}

Notes: The table reports the regime classification measure (RCM2) of Baele (forthcoming) for the bivariate model for the short rate changes for the US-UK and US-Germany: Model A: Switching-Level ARCH with $\beta_{01}^{i}=\beta_{02}^{i}$. Model B: Level SWARCH with $\gamma_{1}^{i}=\gamma_{2}^{i}$. Model C: Switching-Level with $\beta_{01}^{i}=\beta_{02}^{i}$. Model D: Level switching-volatility with $\gamma_{1}^{i}=$ $\gamma_{2}^{i}$ 
Table 9: Standardized Residuals - Bivariate Models

Panel A: US-UK

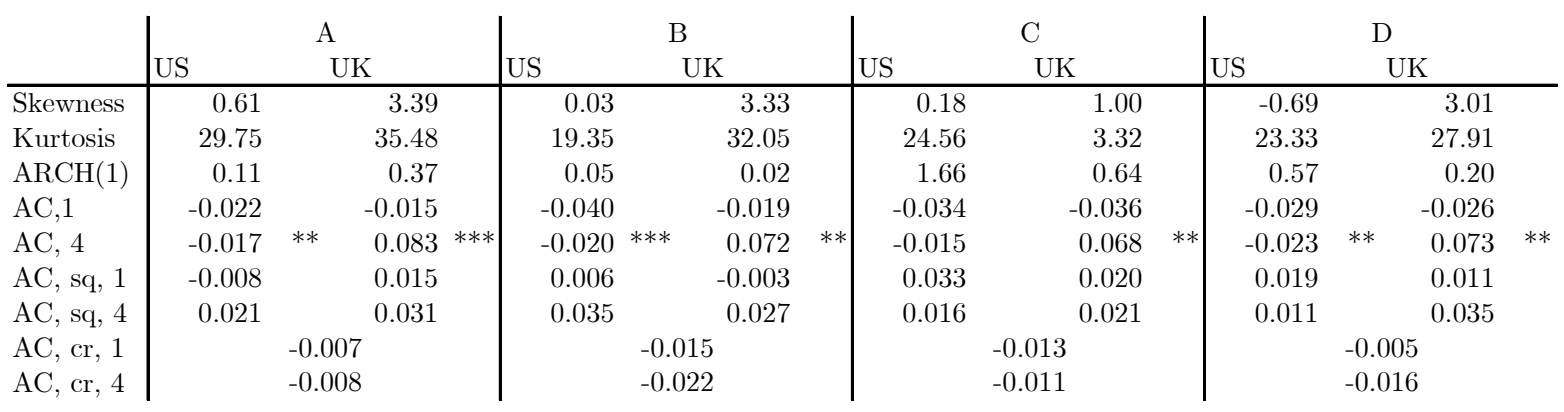

Panel B: US-Germany

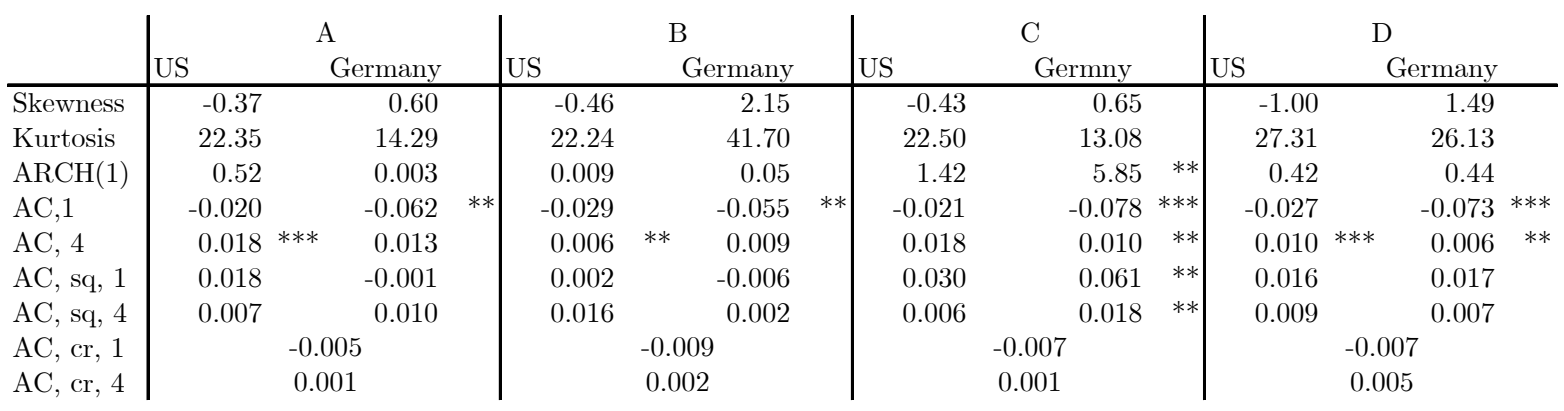

Notes: The table reports various statistics for the standardized residuals from the bivariate model for the short rate changes for the US-UK and US-Germany: Model A: SwitchingLevel ARCH with $\beta_{01}^{i}=\beta_{02}^{i}$. Model B: Level SWARCH with $\gamma_{1}^{i}=\gamma_{2}^{i}$. Model C: Switching-Level with $\beta_{01}^{i}=\beta_{02}^{i}$. Model D: Level switching-volatility with $\gamma_{1}^{i}=\gamma_{2}^{i}$. The following statistics are reported: Skewness, Kurtosis, LM test statistic for ARCH(1), autocorrelation (order 1 and 4), autocorrelation for squared standardized residuals (order 1 and 4), and autocorrelation for cross multiplied standardized residuals (order 1 and 4). (Except for the skewness and kurtosis) $*$, **, *** indicates significance at $10 \%, 5 \%$, and $1 \%$ level of significance. 
Table 10: Predictive Power - Bivariate Models

Panel A: US-UK

\begin{tabular}{l|cccc} 
& $\mathrm{A}$ & $\mathrm{B}$ & $\mathrm{C}$ & $\mathrm{D}$ \\
\hline US volatility & 0.23 & 0.28 & 0.33 & 0.34 \\
UK volatility & 0.11 & 0.11 & 0.12 & 0.12 \\
Covariance & 0.13 & 0.16 & 0.21 & 0.22
\end{tabular}

Panel B: US-Germany

\begin{tabular}{l|cccc} 
& \multicolumn{1}{|c}{$\mathrm{A}$} & $\mathrm{B}$ & $\mathrm{C}$ & $\mathrm{D}$ \\
\hline US volatility & 0.35 & 0.31 & 0.36 & 0.35 \\
German vol. & 0.09 & 0.09 & 0.13 & 0.14 \\
Covariance & 0.15 & 0.16 & 0.24 & 0.24
\end{tabular}

Notes: For the bivariate models for US-UK and US-Germany, the table reports the $R^{2} \mathrm{~s}$ from regressing the absolute short rate change $\left(\left|r_{t}^{i}-r_{t-1}^{i}\right|\right)$ on its estimated volatility $\left(\sqrt{\widehat{h_{t}^{i}}}\right)$. for $i=1,2$, and from regressing $\left(\left|r_{t}^{1}-r_{t-1}^{1}\right|\left|r_{t}^{2}-r_{t-1}^{2}\right|\right.$ on the estimated covariance $\left(\widehat{h_{t}^{12}}\right)$. A: Switching-Level ARCH with $\beta_{01}^{i}=\beta_{02}^{i}$. Model B: Level SWARCH with $\gamma_{1}^{i}=\gamma_{2}^{i}$. Model C: Switching-Level with $\beta_{01}^{i}=\beta_{02}^{i}$. Model D: Level switchingvolatility with $\gamma_{1}^{i}=\gamma_{2}^{i}$. 


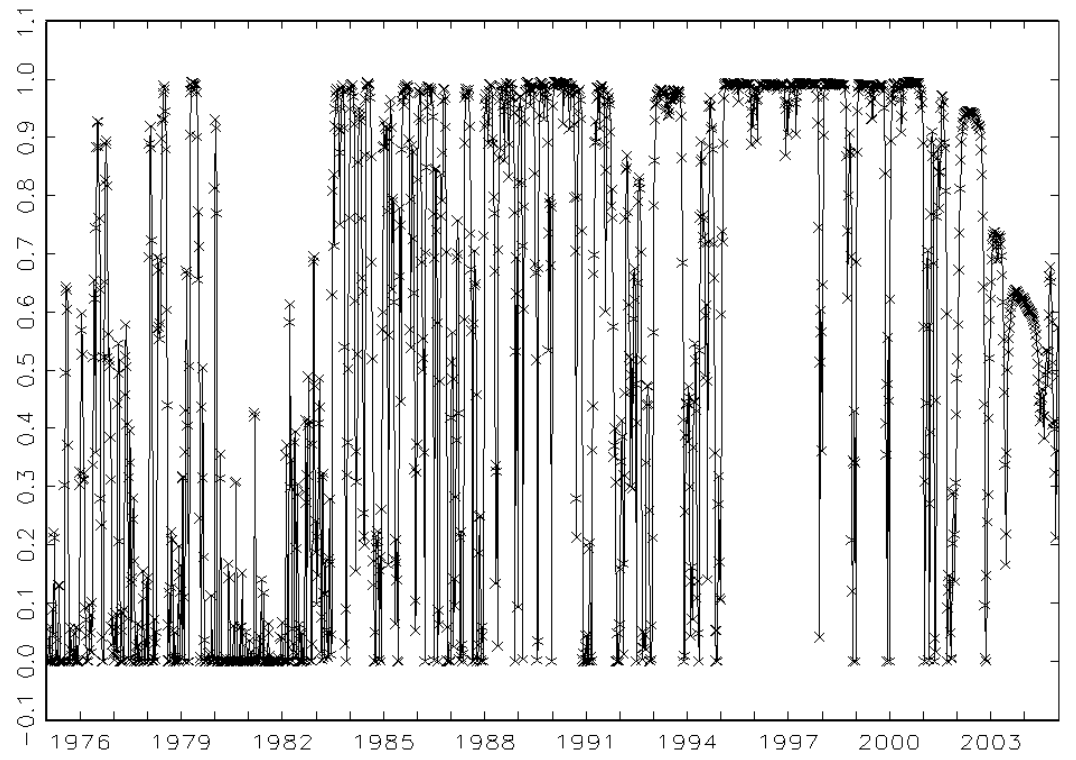

Figure 1:

Note: The figure shows the smoothed state 1 probabilities for the US based on the univariate Model V. 


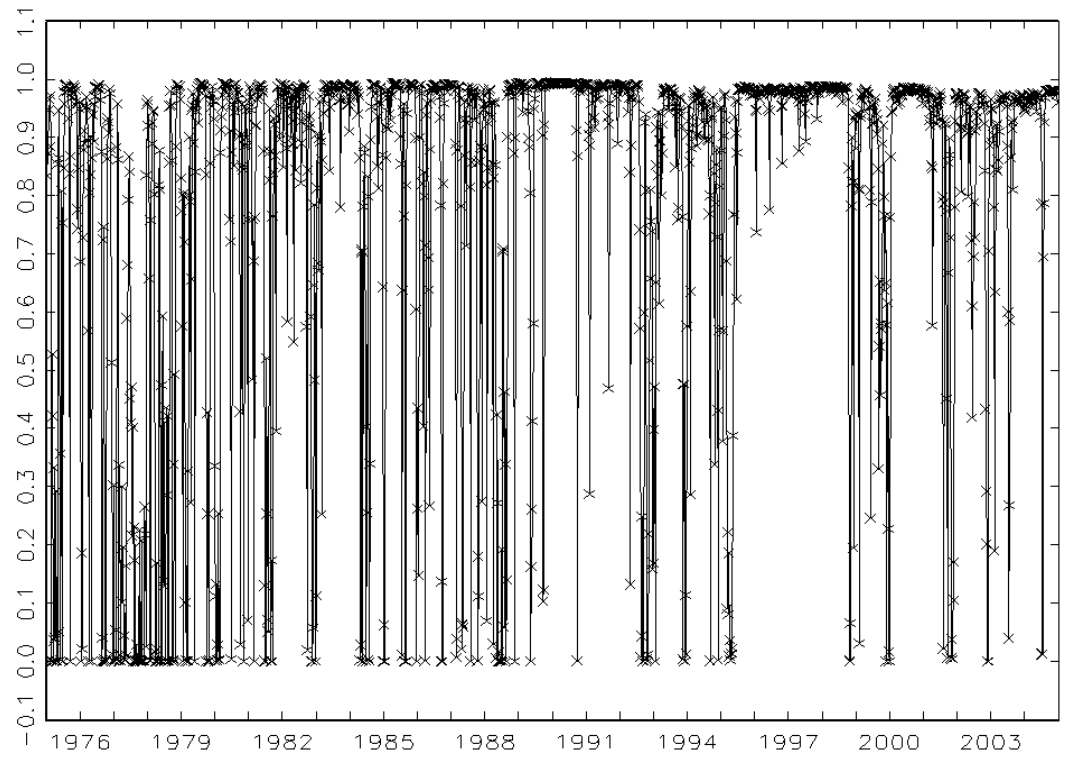

Figure 2:

Note: The figure shows the smoothed state 1 probabilities for the UK based on the univariate Model V. 


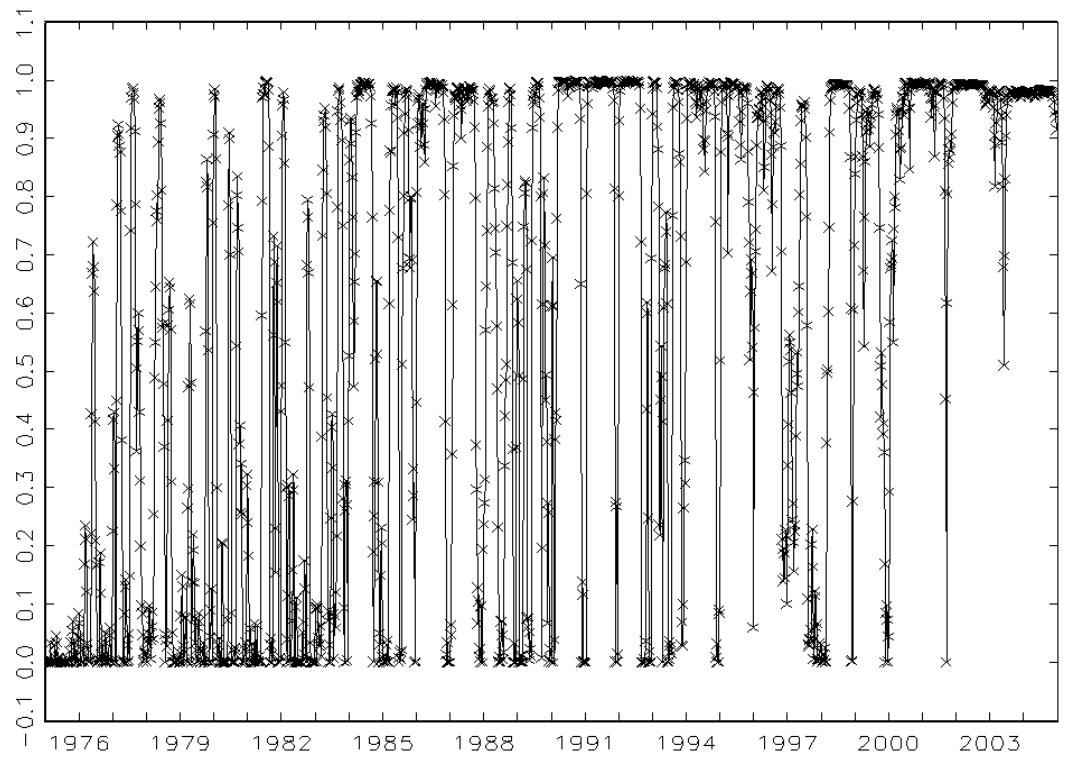

Figure 3:

Note: The figure shows the smoothed state 1 probabilities for Germany based on the univariate Model V. 


\section{Working Papers from Finance Research Group}

F-2005-03 Charlotte Christiansen: Level-ARCH Short Rate Models with Regime Switching: Bivariate Modeling of US and European Short Rates.

F-2005-02 Charlotte Christiansen, Juanna Schröter Joensen and Jesper Rangvid: Do more economists hold stocks?

F-2005-01 Michael Christensen: Danish mutual fund performance - selectivity, market timing and persistence.

F-2004-01 Charlotte Christiansen: Decomposing European bond and equity volatility. 
ISBN 87-7882-060-X

Department of Accounting, Finance and Logistics

Aarhus School of Business

Fuglesangs Allé 4

DK-8210 Aarhus V - Denmark

Tel. +4589486688

Fax +4586150188

www.asb.dk 